Sharif University of Technology
Scientia Iranica
Transactions E: Industrial Engineering
http://scientiairanica.sharif.edu

\title{
Pricing in two competing supply chains based on market power and market size under centralized and decentralized structures
}

\author{
N. Khanlarzade ${ }^{\mathrm{a}}$, S.H. Zegordi ${ }^{\mathrm{a}, *}$, and I. Nakhai Kamalabadi ${ }^{\mathrm{b}}$ \\ a. Faculty of Industrial \& Systems Engineering, Tarbiat Modares University, Tehran, Iran. \\ b. Department of Industrial Engineering, Faculty of Engineering, University of Kurdistan, Sanandaj, Iran. \\ Received 8 April 2018; received in revised form 26 March 2019; accepted 25 June 2019
}

\section{KEYWORDS \\ Supply chain \\ management; \\ Price competition; \\ Market size; \\ Nash game; \\ Stackelberg game.}

\begin{abstract}
This study considered the competition between two multi-echelon supply chains with identical structures on price under two market power structures. For this purpose, two different scenarios were developed. In the first scenario, both supply chains decided simultaneously (the Nash game). In the second scenario, due to the imbalance of power between the two supply chains, the Stackelberg game was adopted in the model. The paper investigated the effects of different relations between the market sizes of supply chains and the supply chain structures on price and profit along with the analysis of power in the market. Based on these assumptions, it was found that the supply chains did not always involve the second-mover advantage in the price Stackelberg game. Furthermore, having the centralized structure, both of the supply chains benefited from the presence of a leader in the market for different combinations of market size. Moreover, the relationship between price and profit was analyzed given the size of the market in different scenarios rather than through provision of numerical examples.
\end{abstract}

(C) 2021 Sharif University of Technology. All rights reserved.

\section{Introduction}

The supply chain is claimed to be the collective effort of several companies, which leads to timely reaction to customer demands and, ultimately, delivery of the products to the final customers. Thus, competition among companies has created a new type of competition among the chains. Customers' buying decisions can be influenced by several factors. The price is a

*. Corresponding author. Tel.: +982182883394 E-mail addresses: n.khanlarzade@modares.ac.ir (N. Khanlarzade); Zegordi@modares.ac.ir (S.H. Zegordi); i.nakhai@uok.ac.ir (I. Nakhai Kamalabadi)

doi: $10.24200 /$ sci.2019.50740.1845 very important decision criterion that customers use to compare alternatives. It is essential to ensure the cooperation among the supply chain members in order to have an efficient, effective management of the material and product flow. This cooperation can be a centralized or decentralized process [1]. In a centralized decision-making process, only one decision-maker is assumed to manage the entire supply. By contrast, the participants make their decisions independently, resulting in a non-cooperative supply chain [2].

According to what was mentioned above, the current study aims at investigating the competition between two supply chains. Due to the fact that a real supply chain has more than two levels in the real world, two supply chains with three echelons are considered so that the conditions are closer to reality. In each chain, 
the first level is considered to be a manufacturer, the second level is a distributor, and the third level is a retailer.

In this research, the distributor is an independent company that does the pricing to manage its income. Part of the price increase concerns its costs, and the other part pertains to the profit margin. Pricing power on the part of the distributor can be observed also in papers such as Heydari et al. [3] and Lan et al. [4].

The products of the two chains are substitutable. The competition between supply chains with the same structure is focused on retailer price. They are assumed to be either centralized or decentralized. Based on these two types of structure, the profit and price equilibria are analyzed in the balance and imbalance modes of chain power in the market. The Stackelberg game is conceptually similar to subgame perfect Nash equilibria in dynamic games (due to the precedence of the leader's and the follower's moves). Therefore, the balance achieved in the game is similar to that for a subgame perfect Nash equilibrium (a subgame perfect equilibrium is a refinement of a Nash equilibrium used in dynamic games). The Nash game, however, is considered as a static game.

The key difference between the present research and similar studies is that it considers the impact of simultaneous or sequential moves of two multiechelon supply chains with the same structure on the competition between them. In this study, the impact of supply chain structure, types of movement of the supply chains in the market, and the market sizes of the supply chains on the profit and price of each of them is investigated simultaneously.

The purpose of this research is to specify whether or not new results are achieved from examination of different scenarios of combination of the supply chain structure and power structure and the comparison between them.

In each chain, the manufacturer is considered to be the leader, and the distributor and retailer are the followers. Therefore, there exist two Stackelberg games between the echelons.

The rest of the paper is organized as follows. Relevant studies are reviewed in Section 2. Section 3 is dedicated to the proposed mathematical model and its parameters along with all the scenarios in the Nash and Stackelberg games. In Section 4, equilibrium solutions are extracted from the Game Theory (GT) for the manufacturer, distributor, and retailer prices under various scenarios. Section 5 addresses the effects of the market sizes of the two supply chains on chain profit and sale price. In that section, the general relations of profit (and price) between the Nash and Stackelberg scenarios are extracted for different market sizes of the supply chains. At the end of that section, managerial insights are given for offering the most appropriate power structure between the chains with respect to their structures. Finally, Section 6 summarizes the findings and proposes future research directions.

\section{Literature review}

Manufacturers that produce similar or substitutable products always enter competitions in the markets. Hence, two types of competition are formed in the market for supply chains: 1) competition among the members of one supply chain and 2) competition between the supply chains. Given that many papers have been published on the competition within the supply chain [5-13] the present study focuses on the competition between two supply chains. A review of the relevant papers follows.

The study by McGuire and Staelin [14] on price competition between two suppliers whose products were sold through independent retailers in a duopoly market with two competitive supply chains showed that the decentralized structure was preferred by chains over the centralized structure as the degree of substitution between the products rises. Moorthy [15] linked the concept of strategic interaction to decentralization value. Boyaci and Gallego [16] studied three competitive scenarios between two supply chains. They realized that both chains had selected the centralized structure for their dominant strategies.

Qian [17] studied the price competition between Parallel Distribution Channels (PDCs). That research was, in fact, the first to consider the competition between two supply chains assuming one of the chains as leader. Qian demonstrated that the PDC, moving as the second individual, had competitive advantage. Xiao and Yang [18] investigated the price and service competition between two supply chains, each with a risk-neutral supplier and a risk-averse retailer. Wu et al. [19] developed a competitive model with two supply chains by making simultaneous decisions on price and quantity in the competitive model with one and an indefinite number of time periods between the two chains.

Anderson and Bao [20] investigated the competition between two-level supply chains. They concluded that although horizontal competition intensification reduced the profit of the industry, an acceptable level of competition could increase the profit if the underlying market shares of the supply chains were not widely scattered. Li et al. [21] investigated contract selection by the manufacturer to create coordination in the competition between two supply chains. Two types of supply chain structure were taken into account in the above study: 1) supply chains with two common retailers and 2) supply chains with exclusive retailers. Mahmoodi and Eshghi [22] studied the horizontal chain-to-chain competition based on price. The struc- 
ture of the industry was taken into account in three modes: 1) both chains were centralized; 2) one chain was centralized and the other was decentralized; and 3) both chains were decentralized.

Amin Naseri and Azari Khojasteh [23] investigated a competitive model between two leader-follower supply chains, each with a risk-neutral manufacturer and a risk-averse retailer. Baron et al. [24] developed the work by MacGuire and Staelin [14] further. The results showed that when the demand was deterministic, both strategies of Stackelberg manufacturer and vertical integration were particular modes of the Nash bargaining on the wholesale prices. Price competition between two supply chains was studied by Zheng et al. [25]. They assumed that one of the supply chains was normal and the other was reverse. They further studied the impact of the degree of competition intensity between the two chains and the product return rate of the reverse supply chain on the profit and price equilibria.

Hafezalkotob et al. [26] formulated a competitive model in multi-product green supply chains under government supervision to reduce the environmental pollution cost. They provided a novel approach to construct a model that maximized the government tariffs and profits of the suppliers and manufacturers in all the green supply chains. Taleizadeh and Sadeghi [27] considered two competitive reverse supply chains that competed in collection and refurbishment of used products after their useful lives.

In this regard, papers by $\mathrm{Ha}$ and Tong [28], $\mathrm{Wu}$ [29], and $\mathrm{Li}$ and $\mathrm{Li}$ [30] can be cited. Table 1 shows the studies reviewed in the present section.

The following critiques can be inferred from the review of the related literature shown in Table 1 :

- Most of the previous studies have investigated the competition between two-echelon supply chains in order to simplify the problem. Therefore, in the present study, a three-echelon supply chain is taken into account so that it gets closer to the reality. The number of decision variables of the problem increases as the number of supply chain levels rises to three levels and the complexity of the model thus increases as well;

- It is understood that most of the above studies have investigated their models assuming the Nash relation to hold between the chains, whereas a few studies such as Amin Naseri and Azari Khojasteh [23] and Qian [17] have considered the imbalance of power in the market between the supply chains. Given the market sizes and structures of the supply chains, the Nash and Stackelberg games are compared in this study for recognition of whether or not concurrence or sequence of motion between the chains is in their favor.

Our study extends the literature by analyzing the simultaneous impact of the movement types, market sizes, and structures of supply chains on their profits and prices.

It is clear from the related literature that the previous research has investigated only a special case of chain structures and of the types of game between them. In this study, however, notable results are obtained through investigation of different scenarios of combination of chain structures and power structures between them. In other words, this research is innovative in that it analyzes different scenarios and finally, helps managers make decisions in different conditions of the market and competitors.

This research is conducted based on the activities of two supply chains in the home appliances industry in Iran (as requested by the chains, there is no mention of them in this paper). These two chains are the two main rivals in the Iranian market because of their production of substitutable products. Customers of these types of product are highly sensitive to price. These chains can

Table 1. Summary of the literature on supply chain competition.

\begin{tabular}{|c|c|c|c|c|c|c|}
\hline \multirow[t]{2}{*}{ Paper } & \multicolumn{2}{|c|}{ Structure of the market power } & \multicolumn{2}{|c|}{ Factor competition } & \multicolumn{2}{|c|}{ Number of levels } \\
\hline & Power imbalance & Power balance & Non-price & Price & $2<$ & 2 \\
\hline$[14,15,20,21,22,24,25]$ & & * & & * & & * \\
\hline$[17]$ & & * & & * & * & * \\
\hline$[27]$ & & $*$ & $*$ & & $*$ & $*$ \\
\hline$[23]$ & & $*$ & & $*$ & $*$ & \\
\hline$[18]$ & & $*$ & $*$ & $*$ & & $*$ \\
\hline$[19,29]$ & & $*$ & $*$ & $*$ & & $*$ \\
\hline$[16,26]$ & & $*$ & * & & & $*$ \\
\hline$[28,30]$ & & $*$ & $*$ & & & $*$ \\
\hline This paper & $*$ & & & * & $*$ & $*$ \\
\hline
\end{tabular}


use two structures for selling their goods. For reasons such as historical background, fame, innovation, and other marketing criteria mentioned above, a leader may be assigned in the market. The brands examined in this study have the same level of background and reputation in the market. Thus, one chain can perhaps act as a leader in the market by introducing a new product. The rival chain can compete with the leading chain by producing similar and/or substitutable products. In fact, the proposed model will be functional in any duopoly market with two competitive supply chains with the above conditions.

\section{Model definition}

This section is dedicated to specification of price for the two rival supply chains. The following assumptions are made:

a) Each supply chain consists of three levels;

b) The manufacturer is more influential than the others and makes the initial decision;

c) In each chain, all the members try to maximize their own profit;

d) All the members have complete information about the demand;

e) Demand is a function of price aimed at focusing on the competitive factor;

f) Unit cost (including the costs of goods storage and dispatch, manpower, and damaged goods, etc.) is assumed to be inconsiderable, i.e., zero, for all the supply chain members for the sake of simplicity in solving the model.

Table 2 shows the parameters of the model.

As in the study by Amin Naseri and Azari Khojasteh [23], the demand structure is assumed to be symmetrical between two products here; therefore, the demand function can be rewritten as follows:

$$
D_{i}=\alpha_{i}-\lambda p_{R i}+\mu p_{R j},
$$

where:

$$
i=1,2 ; \quad j=3-i ; \quad \lambda>0, \quad \mu>0 ; \quad \alpha_{i}>0 .
$$

For the above demand function, we have:

$$
\begin{aligned}
\frac{\partial D_{i}}{\partial p_{R i}} & =-(\lambda), \\
\frac{\partial D_{i}}{\partial p_{R j}} & =\mu .
\end{aligned}
$$

Eq. (2) shows that demand decreases as product price increases, and Eq. (3) demonstrates that increase in the price of one product increases the demand for another product.

For examination of the effect of competition, all the model parameters are assumed to be known and deterministic. This assumption has also been made by some other researchers [30,32]. We also assume that:

$$
\lambda>\mu
$$

which has been taken into account in previous studies such as Amin Naseri and Azari Khojasteh [23], Modak et al. [5], Wang et al. [9], and denotes that the customers of a particular product are more sensitive to the price of that product than to the competitor's price. The problem is considered in two modes as follows:

\section{Mode 1: Both of the supply chains are central- ized (CC)}

In this case, the following two scenarios are possible according to the balance or imbalance mode of market power between the chains:

Scenario I (N-C): Simultaneous selection of price by both chains;

Scenario II (S-C): Consecutive selection of price by both chains.

Mode 2: Both of the supply chains are decentralized (DD)

In this case, both of the supply chains are decentralized. Thus, we have:

Table 2. Parameters and indices of the model.

\begin{tabular}{cl}
\hline$i$ & Supply chain index \\
$\lambda$ & Responsiveness of each product's demand to its price \\
$\mu$ & Responsiveness of each product's demand to its competitor's price \\
$w_{M i}$ & Manufacturer's price in the $i$ th chain \\
$w_{D i}$ & Distributor's price in the $i$ th chain \\
$p_{R i}$ & Retailer's price in the $i$ th chain \\
$\alpha_{i}$ & Market base of product (supply chain) $i$ th \\
$c_{M}$ & Production cost of the manufacturer \\
$\alpha_{i}$ & measures the size of product $i$ 's market [31]
\end{tabular}


Scenario I (N-D): Simultaneous selection of price by both chains;

Scenario II (S-D): Consecutive selection of price by both chains.

In scenarios $\mathrm{S}-\mathrm{C}$ and $\mathrm{S}-\mathrm{D}$, we assume that one chain, which acts as the leader, is stronger than the other in the market. Without loss of generality, it is assumed in the Stackelberg game that the first chain is the leader, and the second one acts as the follower. Additionally, in scenarios S-C and S-D, there will be two and three Stackelberg games, respectively.

\section{Equilibrium analysis}

In this section, we intend to obtain the price equilibrium in different scenarios. In each scenario, stepwise and consecutive procedures are followed to determine the decision variable equilibrium.

For a centralized supply chain, the profit function is as follows:

$$
\begin{aligned}
& \Pi_{s c}^{i}=\left(p_{R i}-c_{M}\right) D_{i}=\left(p_{R i}-c_{M}\right)\left(\alpha_{i}-\lambda p_{R i}+\mu p_{R j}\right), \\
& i=1,2, \quad j=3-i .
\end{aligned}
$$

Moreover, if the supply chain is decentralized, we have:

$$
\begin{aligned}
& \prod_{M}^{i}=\left(w_{M i}-c_{M}\right)\left(\alpha_{i}-\lambda p_{R i}+\mu p_{R j}\right), \\
& \prod_{D}^{i}=\left(w_{D i}-w_{M i}\right)\left(\alpha_{i}-\lambda p_{R i}+\mu p_{R j}\right), \\
& \prod_{R}^{i}=\left(p_{R i}-w_{D i}\right)\left(\alpha_{i}-\lambda p_{R i}+\mu p_{R j}\right),
\end{aligned}
$$

where $i=1,2, j=3-i$.

Scenario $\mathrm{N}$-C. In this scenario, both supply chains concurrently specify $p_{R i}^{*}$ to maximize their profits. The procedure is solved as follows:

1. Differentiation of the objective function with respect to the decision variable $\left(p_{R i}\right)$;

2. Solving the equations $\frac{\partial \Pi_{s c}^{1}}{\partial p_{R 1}}=0$ and $\frac{\partial \Pi_{s c}^{2}}{\partial p_{R 2}}=0$ simultaneously and specifying the retailer price equilibrium in each chain.

Thus, the decision variable equilibrium values in each chain are as follows:

$$
\begin{aligned}
& p_{R 1}^{*}=\frac{2 \lambda\left(\lambda c_{M}+\alpha_{1}\right)+\mu\left(\lambda c_{M}+\alpha_{2}\right)}{4 \lambda^{2}-\mu^{2}}, \\
& p_{R 2}^{*}=\frac{2 \lambda\left(\lambda c_{M}+\alpha_{2}\right)+\mu\left(\lambda c_{M}+\alpha_{1}\right)}{4 \lambda^{2}-\mu^{2}} .
\end{aligned}
$$

Theorem 4.1. The profit of the supply chain in Eq. (5) is strictly concave.

Proof. In the centralized mode, for the $i$ th supply chain (Eq. (5)), we have $\frac{\partial \Pi_{s i}^{i}}{\partial p_{R i}}=\lambda\left(c_{M}-2 p_{R i}\right)+\alpha_{1}+$ $\mu p_{R j}$. On the other hand, $\frac{\partial^{2} \Pi_{s c}^{i}}{\partial \mathrm{p}_{R i}^{2}}=-2 \lambda$, since $\lambda>0$, $\frac{\partial^{2} \Pi_{s c}^{i}}{\partial \mathrm{p}_{R i}^{2}}<0$. As a result, $\Pi_{R}^{i}$ is strictly concave.

Eq. (5) is strictly concave; consequently, the values obtained for $\mathrm{p}_{R 1}^{*}$ and $\mathrm{p}_{R 2}^{*}$ are optimal and unique.

Scenario $\boldsymbol{S}$ - $\boldsymbol{C}$. The procedures of the leader-follower problem are solved as follows:

(i) Follower problem:

(1) Differentiation of Function (5) with respect to $p_{R 2}$

(2) Solving the equation $\frac{\partial \Pi_{s c}^{2}}{\partial p_{R 2}}=0$ and obtaining the price equilibrium solution;

$$
p_{R 2}=f\left(p_{R 1}\right)=\frac{\lambda c_{M}+\alpha_{2}+\mu p_{R 1}}{2 \lambda},
$$

$p_{R 2}=f\left(p_{R 1}\right)$ means that $p_{R 2}$ is a function of $p_{R 1}$.

(ii) Leader problem:

(1) Replacement of Eq. (9) in the profit function;

(2) Specification of the first derivative of the function with respect to $p_{R 1}$;

(3) Solving the equation $\frac{\partial \Pi_{s c}^{1}}{\partial p_{R}}=0$ and specifying the response of the equilibrium to the price:

$$
p_{R 1}^{*}=\frac{2 \lambda\left(\lambda c_{M}+\alpha_{1}\right)+\mu\left(\lambda c_{M}+\alpha_{2}\right)-c_{M} \mu^{2}}{4 \lambda^{2}-2 \mu^{2}} .
$$

Thus, the decision variable equilibrium in the follower chain is obtained by the equation shown in Box I.

Scenario $N-D$. The solution procedure is as follows:

(1) Differentiation of Function (8) with respect to $p_{R i}$.

$$
p_{R 2}^{*}=\frac{\lambda c_{M}+\alpha_{2}+\left\{\mu\left(2 \lambda\left(\lambda c_{M}+\alpha_{1}\right)+\mu\left(\lambda c_{M}+\alpha_{2}\right)-c_{M} \mu^{2}\right) /\left(4 \lambda^{2}-2 \mu^{2}\right)\right\}}{2 \lambda} .
$$


(2) Solving the equations $\frac{\partial \Pi_{R}^{1}}{\partial p_{R 1}}=0$ and $\frac{\partial \Pi_{R}^{2}}{\partial p_{R 2}}=0$ simultaneously and specifying the retailer prices as follows:

$$
\begin{aligned}
p_{R 1} & =f\left(w_{D 1}, w_{D 2}\right) \\
& =\frac{2 \lambda\left(\lambda w_{D 1}+\alpha_{1}\right)+\mu\left(\lambda w_{D 2}+\alpha_{2}\right)}{4 \lambda^{2}-\mu^{2}}, \\
p_{R 2} & =f\left(w_{D 1}, w_{D 2}\right) \\
& =\frac{2 \lambda\left(\lambda w_{D 2}+\alpha_{2}\right)+\mu\left(\lambda w_{D 1}+\alpha_{1}\right)}{4 \lambda^{2}-\mu^{2}} .
\end{aligned}
$$

Theorem 4.2. The retailer's profit function is strictly concave.

Proof. For $\Pi_{R}^{i}$, we have:

$$
\frac{\partial \Pi_{R}^{i}}{\partial p_{R i}}=\lambda\left(-2 p_{R i}+w_{D 1}\right)+\alpha_{1}+\mu p_{R j} .
$$

On the other hand, $\frac{\partial^{2} \Pi_{R}^{i}}{\partial\left(p_{R i}\right)^{2}}=-2 \lambda$. Because $\lambda>0$, $\frac{\partial^{2} \Pi_{R}^{i}}{\partial\left(p_{R i}\right)^{2}}<0$. As a result, $\Pi_{R}^{i}$ is strictly concave.

Since the objective function of the retailer is concave, the value obtained for $p_{R i}$ is optimal and unique.

(3) Replacement of Eqs. (10) and (11) in the profit function of distributors, as a result of which:

$$
\begin{aligned}
& \Pi_{D}^{1}=f\left(w_{M 1}, w_{D 1}, w_{D 2}\right), \text { and: } \\
& \Pi_{D}^{2}=f\left(w_{M 2}, w_{D 1}, w_{D 2}\right)
\end{aligned}
$$

(4) Specification of the first derivative of the distributor profit function with respect to $w_{D 1}$ and $w_{D 2}$.

(5) Solving the equations $\frac{\partial \Pi_{D}^{1}}{\partial w_{D 1}}=0$ and $\frac{\partial \Pi_{D}^{2}}{\partial w_{D 2}}=0$ simultaneously and specifying the prices of distributors as follows:

$$
\begin{aligned}
w_{D 2} & =f\left(w_{M 1}, w_{M 2}, s_{1}, s_{2}\right) \\
& =A_{1}\left(\mu\left(2 \lambda^{3}-\lambda \mu^{2}\right) w_{M 1}+2\left(-2 \lambda^{2}+\mu^{2}\right)^{2}\right. \\
& \left.w_{M 2}+\alpha_{1}\left(6 \lambda^{2} \mu-2 \mu^{3}\right)+\alpha_{2}\left(8 \lambda^{3}-3 \lambda \mu^{2}\right)\right), \\
w_{D 1} & =f\left(w_{M 1}, w_{M 2}\right)=A_{1}\left(2\left(-2 \lambda^{2}+\mu^{2}\right)^{2} w_{M 1}\right. \\
& +\mu\left(2 \lambda^{3}-\lambda \mu^{2}\right) w_{M 2}+\alpha_{1}\left(8 \lambda^{3}-3 \lambda \mu^{2}\right) \\
& \left.+\alpha_{2}\left(6 \lambda^{2} \mu-2 \mu^{3}\right)\right) .
\end{aligned}
$$

Theorem 4.3. The distributor's profit function (Eq. (7)) is strictly concave.

Proof. Given the supplier's profit function in step (3), we have:

$$
\frac{\partial^{2} \Pi_{D}^{1}}{\partial\left(w_{D 1}\right)^{2}}=\frac{\partial^{2} \Pi_{D}^{2}}{\partial\left(w_{D 2}\right)^{2}}=\frac{2 \lambda\left(\mu^{2}-2 \lambda^{2}\right)}{4 \lambda^{2}-\mu^{2}} .
$$

Since all the parameters are positive, the above relation is always negative. Therefore, we have $\frac{\partial^{2} \Pi_{D}^{1}}{\partial\left(w_{D 1}\right)^{2}}=$ $\frac{\partial^{2} \Pi_{D}^{2}}{\partial\left(w_{D 2}\right)^{2}}<0$, and $\Pi_{D}^{1}$ and $\Pi_{D}^{2}$ are also concave.

Eq. (7) is strictly concave; consequently, the value obtained for $w_{D i}$ is optimal and unique.

(6) Replacement of Eqs. (10)-(13) in the profit function of the manufacturer, as a result of which:

$$
\begin{aligned}
& \Pi_{M}^{1}=f\left(w_{M 1}, w_{M 2}\right) \text { and } \\
& \Pi_{M}^{2}=f\left(w_{M 1}, w_{M 2}\right) .
\end{aligned}
$$

(7) Specification of the first derivative of the manufacturer's profit function $\left(\Pi_{M}^{i}\right)$ with respect to $w_{M i}$.

(8) Solving the following equations simultaneously:

$$
\frac{\partial \Pi_{M}^{1}}{\partial w_{M 1}}=0, \quad \frac{\partial \Pi_{M}^{2}}{\partial w_{M 2}}=0 .
$$

Finally, the manufacture's price equilibrium is as follows:

$$
\begin{aligned}
& w_{M 1}^{*}=A_{2}\left\{A_{3} \alpha_{1}+A_{4} \alpha_{2}+A_{5}\right\}, \\
& w_{M 2}^{*}=A_{2}\left\{A_{4} \alpha_{1}+A_{3} \alpha_{2}+A_{5}\right\} .
\end{aligned}
$$

Theorem 4.4. Function (6) is strictly concave.

Proof. For this function:

$$
\frac{\partial^{2} \Pi_{M}^{1}}{\partial\left(w_{M 1}\right)^{2}}=\frac{-32 \lambda^{7}+52 \lambda^{5} \mu^{2}-26 \lambda^{3} \mu^{4}+4 \lambda \mu^{6}}{64 \lambda^{6}-84 \lambda^{4} \mu^{2}+33 \lambda^{2} \mu^{4}-4 \mu^{6}} .
$$

For a concave manufacture profit function, it is enough to have $\frac{\partial^{2} \Pi_{M}^{1}}{\partial\left(w_{M 1}\right)^{2}}<0$. Since all the parameters are positive and $\lambda>\mu$, it is obvious that $\frac{\partial^{2} \Pi_{M}^{1}}{\partial\left(w_{M 1}\right)^{2}}<0$. Therefore, $\Pi_{M}^{1}$ is strictly concave. All of the above issues are true for $\Pi_{M}^{2}$ as well.

As a result of Theorem 4.4, it can be stated that the values obtained for $w_{M i}^{*}$ are optimal and unique.

Therefore, the optimal distributor and retailer prices are respectively as follows:

$$
\begin{aligned}
w_{D 1}^{*} & =A_{1} A_{2}\left\{A_{6} \alpha_{1}+A_{7} \alpha_{2}+A_{8}\right\}, \\
w_{D 2}^{*} & =A_{1} A_{2}\left\{A_{7} \alpha_{1}+A_{6} \alpha_{2}+A_{8}\right\}, \\
p_{R 1}^{*} & =\frac{A_{1} A_{2}}{\left(4 \lambda^{2}-\mu^{2}\right)}\left\{\frac{A_{3} A_{4}}{\mu} \alpha_{1}+\frac{\left(A_{4}\right)^{2}}{\mu} \alpha_{2}\right. \\
& \left.+A_{8} \lambda(2 \lambda+\mu)\right\},
\end{aligned}
$$




$$
\begin{aligned}
p_{R 2}^{*}= & \frac{A_{1} A_{2}}{\left(4 \lambda^{2}-\mu^{2}\right)}\left\{\frac{\left(A_{4}\right)^{2}}{\mu} \alpha_{1}+\frac{A_{3} A_{4}}{\mu} \alpha_{2}\right. \\
& \left.+A_{8} \lambda(2 \lambda+\mu)\right\} .
\end{aligned}
$$

More information about the above parameters $\left(A_{1}, A_{2}, \ldots\right)$ is available in Appendix A.

Scenario $\boldsymbol{S}-\boldsymbol{D}$. The solution procedure is as follows:

(i) Follower problem:

(1) Calculating the first derivative of the retailer function with respect to $p_{R 2}$ and solving $\frac{\partial \pi_{R}^{2}}{\partial p_{R 2}}=0$, as a result of which we have:

$$
p_{R 2}=f\left(p_{R 1}, w_{D 2}\right)=\frac{\mu p_{R 1}+\lambda w_{D 2}+\alpha_{2}}{2 \lambda} .
$$

(2) Replacement of Eq. (14) in the distributor's profit function that obtains:

$$
\Pi_{D}^{2}=f\left(w_{M 2}, w_{D 2}, p_{R 1}\right) .
$$

(3) Specifying the first derivative of the function and solving $\frac{\partial \Pi_{D}^{2}}{\partial w_{D 2}}=0$ :

$$
w_{D 2}=f\left(p_{R 1}, w_{M 2}\right)=\frac{\mu p_{R 1}+\lambda w_{M 2}+\alpha_{2}}{2 \lambda} .
$$

(4) Replacement of Eqs. (14) and (15) in the manufacturer's profit function, as a result of which $\Pi_{M}^{2}=f\left(w_{M 2}, p_{R 1}\right)$.

(5) Specifying the first derivative of $\Pi_{M}^{2}$ with respect to $w_{M 2}$ and solving the equation $\frac{\partial \Pi_{M}^{2}}{\partial w_{M 2}}=0$ :

$$
w_{M 2}=f\left(p_{R 1}\right)=\frac{\mu p_{R 1}+\lambda c_{M}+\alpha_{2}}{2 \lambda} .
$$

(ii) Leader problem:

(1) Replacement of Eq. (15) in Eq. (14), which obtains $p_{R 2}=f\left(p_{R 1}, w_{M 2}\right)$.

(2) Replacement of Eq. (16) in $p_{R 2}=f\left(p_{R 1}\right.$, $w_{M 2}$ ), as a result of which:

$$
p_{R 2}=f\left(p_{R 1}\right)=\frac{7 \mu p_{R 1}+\lambda c_{M}+7 \alpha_{2}}{8 \lambda} .
$$

(3) Replacement of Eq. (17) in the retailer's profit function, which obtains $\Pi_{R}^{1}=f\left(w_{D 1}, p_{R 1}\right)$.

(4) Specifying the first derivative of $\Pi_{R}^{1}$ with respect to $p_{R 1}$ and solving $\frac{\partial \Pi_{R}^{1}}{\partial p_{R 1}}=0$,

$$
\begin{aligned}
p_{R 1} & =f\left(w_{D 1}\right) \\
& =\frac{1}{2}\left(w_{D 1}+\frac{8 \lambda \alpha_{1}+\lambda \mu c_{M}+7 \mu \alpha_{2}}{8 \lambda^{2}-7 \mu^{2}}\right)_{(18}
\end{aligned}
$$

(5) Replacement of Eq. (18) in Eq. (17), as a result of which we have:

$$
p_{R 2}=f\left(w_{D 1}\right) .
$$

(6) Replacement of Eqs. (19) and (18) in the distributor's profit function, which obtains $\Pi_{D}^{1}=f\left(w_{M 1}, w_{D 1}\right)$.

(7) Specifying the first derivative of $\Pi_{D}^{1}$ with respect to $w_{D 1}$ and solving $\frac{\partial \Pi_{D}^{1}}{\partial w_{D 1}}=0$,

$$
\begin{aligned}
w_{D 1} & =f\left(w_{M 1}\right) \\
& =\frac{1}{2}\left(w_{M 1}+\frac{8 \lambda \alpha_{1}+\lambda \mu c_{M}+7 \mu \alpha_{2}}{8 \lambda^{2}-7 \mu^{2}}\right) .
\end{aligned}
$$

(8) Replacement of Eq. (20) in Eq. (18), as a result of which $p_{R 1}=f\left(w_{M 1}\right)$.

(9) Replacement of Eq. (20) in Eq. (19), which obtains $p_{R 2}=f\left(w_{M 1}\right)$.

(10) Replacement of $p_{R 2}=f\left(w_{M 1}\right)$ and $p_{R 1}=$ $f\left(w_{M 1}\right)$ in the manufacturer's profit function, as a result of which $\Pi_{M}^{1}=f\left(w_{M 1}\right)$.

(11) Specification of the first derivative of the function with respect to $w_{M 1}$.

(12) Solving the equation $\frac{\partial \Pi_{M}^{1}}{\partial w_{M 1}}=0$ and finally, specifying the manufacturer's price equilibrium as follows:

$$
w_{M 1}^{*}=\frac{1}{2}\left(c_{m}+\frac{8 \lambda \alpha_{1}+\lambda \mu c_{M}+7 \mu \alpha_{2}}{8 \lambda^{2}-7 \mu^{2}}\right) .
$$

Therefore, the equilibrium solutions of the other decision variables are obtained by the equations shown in Box II.

\section{Analytical results with respect to market size}

In this section, a comparison is made between the equilibria of retail prices and profits of the chains in different scenarios given both equality and inequality in the market sizes of the supply chains. For this purpose, analysis is carried out in the following two sections in terms of the structures of the supply chains and the Nash and Stackelberg relations between the chains. It is worth mentioning that the relations between the prices and profits of the chains are analytically determined in different cases. However, it is not possible to generally prove the relations in some cases due to their complexity. Therefore, these relations are specified using numerical examples. For this purpose, the following numerical set is used for the parameters:

$$
Y=\left\{c_{M}=8 ; \alpha \in Z ; \lambda, \mu \in X\right\}
$$


$w_{D 1}^{*}=\frac{1}{2}\left(w_{M 1}^{*}+\frac{8 \lambda \alpha_{1}+\lambda \mu c_{M}+7 \mu \alpha_{2}}{8 \lambda^{2}-7 \mu^{2}}\right)=\frac{8 \lambda\left(\lambda c_{M}+3 \alpha_{1}\right)+3 \mu\left(\lambda c_{M}+7 \alpha_{2}\right)-7 \mu^{2} c_{M}}{32 \lambda^{2}-28 \mu^{2}}$,
$p_{R 1}^{*}=\frac{1}{2}\left(w_{D 1}^{*}+\frac{8 \lambda \alpha_{1}+\lambda \mu c_{M}+7 \mu \alpha_{2}}{8 \lambda^{2}-7 \mu^{2}}\right)=\frac{8 \lambda\left(\lambda c_{M}+7 \alpha_{1}\right)+7 \mu\left(\lambda c_{M}+7 \alpha_{2}\right)-7 \mu^{2} c_{M}}{64 \lambda^{2}-56 \mu^{2}}$,
$w_{M 2}^{*}=\frac{\mu p_{R 1}^{*}+\lambda c_{M}+\alpha_{2}}{2 \lambda}=\frac{c_{M}(7 \lambda+\mu)+\alpha_{2}+\left\{\frac{8 \lambda\left(\lambda^{2} c_{M}+7 \lambda \alpha_{2}+7 \mu \alpha_{1}\right)}{8 \lambda^{2}-7 \mu^{2}}\right\}}{16 \lambda}$,
$w_{D 2}^{*}=\frac{\mu p_{R 1}^{*}+\lambda w_{M 2}^{*}+\alpha_{2}}{2 \lambda}=\frac{64 \lambda^{3} c_{M}+7 \lambda \mu\left(24 \alpha_{1}-5 \mu c_{M}\right)-21 \mu^{2}\left(\alpha_{2}+\lambda \mu\right)+24 \lambda^{2}\left(8 \alpha_{2}+\mu c_{M}\right)}{32\left(8 \lambda^{3}-7 \lambda \mu^{2}\right)}$,
$p_{R 2}^{*}=\frac{\mu p_{R 1}^{*}+\lambda w_{D 2}^{*}+\alpha_{2}}{2 \lambda}=\frac{1}{64}\left(c_{M}+\frac{7 \alpha_{2}}{\lambda}+\frac{7 \mu c_{M}}{\lambda}+\frac{56\left(\lambda^{2} c_{M}+7 \lambda \alpha_{2}+7 \mu \alpha_{1}\right)}{8 \lambda^{2}-7 \mu^{2}}\right)$.

Box II

where:

$$
\begin{aligned}
& Z=(\text { Market Size })= \\
& \qquad\left\{\begin{array}{l}
\alpha_{1}=\alpha_{2}=100, \quad \text { if } \alpha_{1}=\alpha_{2} \\
\alpha_{1}=100, \text { and } \alpha_{2}=200, \quad \text { if } \alpha_{1}<\alpha_{2} \\
\alpha_{1}=200, \text { and } \alpha_{2}=100, \text { if } \alpha_{1}>\alpha_{2}
\end{array}\right.
\end{aligned}
$$

Given that $\lambda>\mu, X$ is defined as follows:

$$
\begin{gathered}
X=\{0.1 \leq \lambda \leq 2,0.01 \leq \mu \leq \lambda-0.01 ; \lambda=\lambda+0.1, \\
\mu=\mu+0.01\} .
\end{gathered}
$$

\subsection{Comparison of the Nash and Stackelberg relations}

Given the structures of the supply chains, the profits and sale prices of the products in the Nash and Stackelberg models are compared in two separate sections.

\subsubsection{CC structure}

Assume that $\alpha_{1}=\alpha_{2}=\alpha$. The price equilibria and profits of the supply chains with the same market size in different scenarios are shown in Table 3 from which the following theorem can be extracted:

Theorem 5.1. Assuming that $\alpha_{1}=\alpha_{2}$, we have:
1. $p_{R 1}^{S}>p_{R 1}^{N}$,
2. $p_{R 1}^{S}>p_{R 2}^{N}$,
3. $p_{R 2}^{S}>p_{R 2}^{N}$,
4. $p_{R 2}^{S}>p_{R 1}^{N}$,
5. $\Pi_{1}^{S}>\Pi_{1}^{N}$
6. $\Pi_{1}^{S}>\Pi_{2}^{N}$,
7. $\Pi_{2}^{S}>\Pi_{2}^{N}$
8. $\Pi_{2}^{S}>\Pi_{1}^{N}$.

This theorem is proven in Appendix B.

Assume that $\boldsymbol{\alpha}_{\mathbf{1}} \neq \boldsymbol{\alpha}_{\mathbf{2}}$. In this section, the difference in price and profit between the Nash and Stackelberg modes will be obtained as shown in Box III.

Theorem 5.2. If the centralized supply chains have different market sizes, then by using the above equations, we will have:

$$
\begin{array}{ll}
\text { 1. } p_{R 1}^{S}>p_{R 1}^{N}, & \text { 2. } p_{R 2}^{S}>p_{R 2}^{N}, \\
\text { 3. } \Pi_{1}^{S}>\Pi_{1}^{N}, & \text { 4. } \Pi_{2}^{S}>\Pi_{2}^{N} .
\end{array}
$$

This theorem is proven in Appendix B.

For a conclusion to be drawn, other relations between the profits and sale prices of the supply chains should be evaluated. Due to the complexity of these relations, the numerical set $\mathrm{Y}$ is used in this section to specify the expected relations.

These relations are shown in Table C.1 (the table is available in Appendix $\mathrm{C}$ ).

Result 5.1. For two centralized supply chains, the following conditions hold.

Regardless of the market sizes of the two chains, both chains receive more profits in the market power imbalance mode than in market power balance. Therefore, the presence of a leader in the market is beneficial to both chains (whether as a follower or as a leader).

The following reasons seem to account for the occurrence of this result:

- Due to the popularity of the brand or innovative activities and novel decisions of the leader, the follower has to improve and develop its activities and 
Table 3. Profit and price equilibria of centralized supply chains with the same market size.

\begin{tabular}{ccc}
\hline & Profit and price equilibria in N-C & Profit and price equilibria in S-C \\
\hline$p_{R 1}$ & $\frac{\lambda c_{M}+\alpha}{2 \lambda-\mu}$ & $\frac{2 \lambda\left(\lambda c_{M}+\alpha\right)+\mu\left(\lambda c_{M}+\alpha\right)-\mu^{2} c_{M}}{4 \lambda^{2}-2 \mu^{2}}$ \\
$p_{R 2}$ & $\frac{\lambda c_{M}+\alpha}{2 \lambda-\mu}$ & $\frac{\lambda c_{M}+\alpha+\left(\mu\left(2 \lambda\left(\lambda c_{M}+\alpha\right)+\mu\left(\lambda c_{M}+\alpha\right)-\mu^{2} c_{M}\right)\right.}{2 \lambda\left(4 \lambda^{2}-2 \mu^{2}\right)}$ \\
$\Pi_{1}$ & $\frac{\lambda\left(-\lambda c_{M}+\alpha+\mu c_{M}\right)^{2}}{(-2 \lambda+\mu)^{2}}$ & $\frac{(\mu+2 \lambda)^{2}\left(-\lambda c_{M}+\alpha+\mu c_{M}\right)^{2}}{16 \lambda^{3}-8 \lambda \mu^{2}}$ \\
$\Pi_{2}$ & $\frac{\lambda\left(-\lambda c_{M}+\alpha+\mu c_{M}\right)^{2}}{(-2 \lambda+\mu)^{2}}$ & $\frac{\left(-4 \lambda^{2}-2 \lambda \mu+\mu^{2}\right)^{2}\left(-\lambda c_{M}+\alpha+\mu c_{M}\right)^{2}}{16 \lambda\left(-2 \lambda^{2}+\mu^{2}\right)^{2}}$ \\
\hline
\end{tabular}

$$
\begin{aligned}
p_{R 1}^{S}-p_{R 1}^{N} & =\frac{\mu^{2}\left(-2 \lambda^{2} c_{M}+\lambda\left(2 \alpha_{1}+\mu c_{M}\right)+\mu\left(\alpha_{2}+\mu c_{M}\right)\right)}{2\left(8 \lambda^{4}-6 \lambda^{2} \mu^{2}+\mu^{4}\right)}, \\
p_{R 2}^{S}-p_{R 2}^{N}= & \frac{\mu^{3}\left(-2 \lambda^{2} c_{M}+\lambda\left(2 \alpha_{1}+\mu c_{M}\right)+\mu\left(\alpha_{2}+\mu c_{M}\right)\right)}{4 \lambda\left(8 \lambda^{4}-6 \lambda^{2} \mu^{2}+\mu^{4}\right)}, \\
\Pi_{1}^{S}-\Pi_{1}^{N}= & \frac{\mu^{4}\left(-2 \lambda^{2} c_{M}+\lambda\left(2 \alpha_{1}+\mu c_{M}\right)+\mu\left(\alpha_{2}+\mu c_{m}\right)\right)^{2}}{8\left(-4 \lambda^{2}+\mu^{2}\right)^{2}\left(2 \lambda^{3}-\lambda \mu^{2}\right)} \\
\Pi_{2}^{S}-\Pi_{2}^{N}= & \frac{\left(4 \lambda^{2}\left(\lambda c_{M}-\alpha_{2}\right)-2 \lambda \mu\left(\lambda c_{m}+\alpha_{1}\right)+\mu^{2}\left(-3 \lambda c_{M}+\alpha_{2}\right)+\mu^{3} c_{M}\right)^{2}}{16 \lambda\left(-2 \lambda^{2}+\mu^{2}\right)^{2}} \\
- & \frac{\lambda\left(-2 \lambda^{2} c_{M}+\mu\left(\alpha_{1}+\mu c_{M}\right)+\lambda\left(2 \alpha_{2}+\mu c_{M}\right)\right)^{2}}{\left(-4 \lambda^{2}+\mu^{2}\right)^{2}} .
\end{aligned}
$$

\section{Box III}

performance to be able to compete in the market. In the Nash game, however, the performance and activities of the two competitors are at the same level.

- In the Nash game, the players are unaware of each other's decisions. In Stackelberg, however, the follower's awareness of the leader's decision allows him to make the best decision and perfect use of market capacity. Therefore, companies gain higher profits here than in Nash.

\subsubsection{DD structure}

Table C.2 shows the price and profit relations in the Nash and Stackelberg scenarios for both conditions of equality and inequality of market sizes in the two chains (the table appears in Appendix C). It is not possible to specify these relations analytically due to the complexity of relations in decentralized chains. Therefore, the numerical set $Y$ is used.

Result 5.2. Regardless of the market sizes of the sup- ply chains in the decentralized structure, the following points can be concluded:

- Comparison of the prices of power balance and imbalance in the market:

1) If the chain is a leader (the first supply chain in the Stackelberg scenario), the retailer price of the chain will be lower than that in the Nash scenario for all values of set $X$. However, the Stackelberg manufacturer and supplier prices of the chain will be lower than those in the Nash scenario if the following conditions are met for the defined values of $\lambda$ and $\mu$ in set $X$ :

Manufacturer price: $3 \lambda / 8<\mu<\lambda$

Distributor price: $6 \lambda / 8<\mu<\lambda$

As observed, con.5, con.9, and con.14 are true in these relations.

2) If the chain is a follower (the second supply chain in the Stackelberg scenario), the manufacturer 
price and distributor price of the chain will be lower than those in the Nash scenario for all values of set $X$. However, the Stackelberg retailer price of the chain will be lower than that in the Nash scenario if the following conditions are met for the values defined for $\lambda$ and $\mu$ in $X$ : $\mu<6 \lambda / 8$.

As observed, con.3, con.6, and con.13 are true in this relation.

- Comparison of the profits in the market power balance and imbalance modes If the chain is a leader, all members of the chain will obtain lower profits than when there is no leader in the market. However, for the following chain in the Stackelberg scenario, the profits of chain members will be greater than those in market power balance. Finally, compared to the state-of-affairs in the market power balance mode, the total profit of the leading supply chain will decrease and that of the following supply chain will increase.

Table 4 (concluded from Results 5.1 and 5.2) indicates the power structure appropriate for the chains to earn maximal profit.

\subsection{Comparison of the Stackelberg relations}

A comparison is made between the profits and sale prices of the products of both supply chains in the Stackelberg scenario (between the leader and the follower) given the structures of the supply chains.

\subsubsection{CC structure}

Assume that $\alpha_{1}=\alpha_{2}=\alpha$.

Theorem 5.3. The relations between the prices and profits of the leading and following centralized supply chains are as follows:

(i) $p_{R 1}^{S}-p_{R 2}^{S}=\frac{\mu^{2}\left(-\lambda c_{M}+\alpha+\mu c_{M}\right)}{8 \lambda^{3}-4 \lambda \mu^{2}}$,

(ii) $\Pi_{1}^{S}-\Pi_{2}^{S}=\frac{-\mu^{3}(4 \lambda+3 \mu)\left(-\lambda c_{M}+\alpha+\mu c_{M}\right)^{2}}{16 \lambda\left(-2 \lambda^{2}+\mu^{2}\right)^{2}}$.

Proof. According to (*) in Appendix B, (i) is always positive. Therefore, $p_{R 1}^{S}>p_{R 2}^{S}$.

It is obvious that (ii) is always negative; therefore, $\Pi_{1}^{S}<\Pi_{2}^{S}$.

Result 5.3. According to Theorem 5.3, the supply chain enjoys the second-mover advantage; i.e., the follower's profit is better than that of the leader.

Since the supply chains have the same market size, their decision-making is based on the Stackelberg game, and price is the decision variable of the game, the follower can obtain a higher profit as the second mover than the first (leader) by offering a lower price.

Assume that $\alpha_{1} \neq \alpha_{2}$. For specification of the relations between the prices and profits of the leading and following supply chains in the Stackelberg game, the relations shown in Box IV, can be considered.

It is not possible to specify the signs of these relations due to the existing complexity. Therefore, the numerical values of set $Y$ are used. It is worth noting that the selected values of set $Y$ are true for $\left(^{*}\right)$ in Appendix B.

i) If $\alpha_{1}<\alpha_{2}$, the following relations will be true for all the defined values of set $Y: p_{R 1}^{S}<p_{R 2}^{S}$ and $\Pi_{1}^{S}<\Pi_{2}^{S}$.

ii) If $\alpha_{1}>\alpha_{2}$, the following relations will be true for all the defined values of set $Y: p_{R 1}^{S}>p_{R 2}^{S}$ and $\Pi_{1}^{S}>\Pi_{2}^{S}$.

Table 4. Advantage of the market power for earning maximal profit.

\begin{tabular}{lcccc}
\hline & & SC1 & SC2 & Entire market \\
\hline Supply-chain structure & CC & Power imbalance & Power imbalance & Power imbalance \\
& DD & Power balance & Power imbalance & - \\
\hline
\end{tabular}

$$
\begin{aligned}
p_{R 1}^{S}-p_{R 2}^{S} & =\frac{4 \lambda^{2}\left(\alpha_{1}-\alpha_{2}\right)-\lambda \mu\left(2 \alpha_{1}-2 \alpha_{2}+\mu c_{M}\right)+\mu^{2}\left(\alpha_{2}+\mu c_{M}\right)}{8 \lambda^{3}-4 \lambda \mu^{2}} \\
\Pi_{1}^{S}-\Pi_{2}^{S} & =\frac{\left(-2 \lambda^{2} c_{m}+\lambda\left(2 \alpha_{1}+\mu c_{M}\right)+\mu\left(\alpha_{2}+\mu c_{M}\right)\right)^{2}}{16 \lambda^{3}-8 \lambda \mu^{2}} \\
& -\frac{\left(4 \lambda^{2}\left(\lambda c_{M}-\alpha_{2}\right)-2 \lambda \mu\left(\lambda c_{M}+\alpha_{1}\right)+\mu^{2}\left(-3 \lambda c_{M}+\alpha_{2}\right)+\mu^{3} c_{M}\right)^{2}}{16 \lambda\left(-2 \lambda^{2}+\mu^{2}\right)^{2}}
\end{aligned}
$$


Result 5.4. For the leading and following supply chains with centralized structures and different market sizes, the following conditions hold:

- If the chain with a smaller market size functions as the leader, the following supply chain will obtain more profit as the second mover with a greater market size than that of the leader;

- If the leading chain has a greater market size, the follower cannot obtain more profit than the leader. Although the follower is the second mover and offers a lower price for selling its product, the market size of the leader leads to achievement of a higher profit than that of the follower.

\subsubsection{DD structure}

Assume that $\alpha_{1}=\alpha_{2}=\alpha$.

Theorem 5.4. The relations shown in Box V hold between the prices and profits of the leading and following chains in the decentralized structure.

Proof. Given assumption $(*)$ (Appendix B) and $\lambda>$ $\mu$, the following relations can be obtained easily:

$$
\begin{aligned}
& p_{R 1}^{S}>p_{R 2}^{S}, \quad w_{D 1}^{S}>w_{D 2}^{S}, \quad w_{M 1}^{S}>w_{M 2}^{S}, \\
& \Pi_{R 1}^{S}<\Pi_{R 2}^{S}, \quad \Pi_{D 1}^{S}<\Pi_{D 2}^{S}, \quad \Pi_{M 1}^{S}<\Pi_{M 2}^{S} .
\end{aligned}
$$

Finally, the relations that are true for the profits of the retailer, supplier, and manufacturer can lead to the following result: $\Pi_{S c 1}^{S}<\Pi_{S c 2}^{S}$.

Result 5.5. For the leading and following chains in the DD structure with the same market size, the following conditions hold.

The sale price of the leading chain is higher than that of the following chain at all levels. Therefore, since the supply chains follow the price Stackelberg game, all levels in the leading chain obtain lower profits than the corresponding levels in the following chain. Thus, there is the second-mover advantage.

Assume that $\boldsymbol{\alpha}_{\mathbf{1}} \neq \boldsymbol{\alpha}_{\mathbf{2}}$. The relations are evaluated in two separate sections given the different market sizes of the chains.

i) If $\alpha_{1}<\alpha_{1}$. The relations between price and profit in this case appear in Table 5 .

ii) If $\alpha_{1}>\alpha_{2}$

Theorem 5.5. When the leader has a larger market size, the following relations are true for the manufacturer, distributor, and retailer prices of the leading and following chains in the DD structure:

$$
p_{R 1}^{S}>p_{R 2}^{S}, \quad w_{D 1}^{S}>w_{D 2}^{S}, \quad w_{M 1}^{S}>w_{M 2}^{S} .
$$

Table 5. The price and profit relations of leader and follower chains in the DD structure.

\begin{tabular}{lcc}
\hline & Price and profit relations & Conditions \\
\hline Price of retailer, distributor, and manufacturer & $p_{R 1}^{S}>p_{R 2}^{S}, w_{D 1}^{S}>w_{D 2}^{S}, w_{M 1}^{S}>w_{M 2}^{S}$ & $C o n .21$ \\
Profit of retailer, distributor, and manufacturer & $\Pi_{R 1}^{S}<\Pi_{R 2}^{S}, \Pi_{D 1}^{S}<\Pi_{D 2}^{S}, \Pi_{M 1}^{S}<\Pi_{M 2}^{S}$ & $\forall \lambda, \mu \in X$ \\
\hline
\end{tabular}

$$
\begin{aligned}
& p_{R 1}^{S}-p_{R 2}^{S}=\frac{49 \mu^{2}\left(-\lambda c_{M}+\alpha+\mu c_{M}\right)}{64\left(8 \lambda^{3}-7 \lambda \mu^{2}\right)}, \\
& \Pi_{R 1}^{S}-\Pi_{R 2}^{S}=\frac{-7 \mu^{2}\left(-\lambda c_{M}+\alpha+\mu c_{M}\right)^{2}\left(384 \lambda^{2}+784 \lambda \mu+399 \mu^{2}\right)}{4096 \lambda\left(8 \lambda^{2}-7 \mu^{2}\right)^{2}} \\
& w_{D 1}^{S}-w_{D 2}^{S}=\frac{21 \mu^{2}\left(-\lambda c_{M}+\alpha+\mu c_{M}\right)}{32\left(8 \lambda^{3}-7 \lambda \mu^{2}\right)}, \\
& \Pi_{D 1}^{S}-\Pi_{D 2}^{S}=\frac{-7 \mu^{2}\left(-\lambda c_{M}+\alpha+\mu c_{M}\right)^{2}\left(384 \lambda^{2}+784 \lambda \mu+399 \mu^{2}\right)}{2048 \lambda\left(8 \lambda^{2}-7 \mu^{2}\right)^{2}} \\
& w_{M 1}^{S}-w_{M 2}^{S}=\frac{7 \mu^{2}\left(-\lambda c_{M}+\alpha+\mu c_{m}\right)}{16\left(8 \lambda^{3}-7 \lambda \mu^{2}\right)}, \\
& \Pi_{M 1}^{S}-\Pi_{M 2}^{S}=\frac{-7 \mu^{2}\left(-\lambda c_{M}+\alpha+\mu c_{M}\right)^{2}\left(384 \lambda^{2}+784 \lambda \mu+399 \mu^{2}\right)}{1024 \lambda\left(8 \lambda^{2}-7 \mu^{2}\right)^{2}} .
\end{aligned}
$$


This theorem is proven in Appendix B.

For the profit of the leading and following chains with the decentralized structure, given the values of set $Y$, if Condition 22 is true, we have $\Pi_{R 1}^{S}>\Pi_{R 2}^{S}$, $\Pi_{D 1}^{S}>\Pi_{D 2}^{S}$, and $\Pi_{M 1}^{S}>\Pi_{M 2}^{S}$.

Result 5.6. For the leading and following chains in the DD structure with different market sizes, the following conditions hold:

- In a market where the leading chain has a smaller market size than the following chain, the leader obtains a lower profit than the follower. Obviously, market size has a significant impact on the profitability of the leading chain; this, in turn, decreases the profit of this chain with respect to the following chain. The supply chain has the second-mover advantage in this case;

- If the leading supply chain has a greater market size, the leader will not always receive greater profit than the follower despite its greater market size. In fact, in the DD structure, the supply chain has the first-mover advantage per Con.22, while it has the second-mover advantage per $(\text { Con.22 })^{c}$, and the follower therefore receives more profit than the leader;

- If the market size of the leader is smaller than those of the other supply chains, the leader's prices will be higher than those of the follower if the following conditions are true for $\lambda$ and $\mu$ for the defined values in set $X: \mu>6 \lambda / 8$;

- If the follower has a smaller market size than the other supply chains, the profit of the leader will be higher than that of the follower when the following condition is met for $\lambda$ and $\mu$ for the defined values in set $X: \mu<6 \lambda / 8$. This means that for $\mu<6 \lambda / 8$, the first-mover advantage is met, while for the other values of $\mu$, there is the second-mover advantage and the leader obtains lower profit than the follower.

Table 6 (extracted from Results 5.3 to 5.6 ) shows that in each structure, the mover has the advantage in the Stackelberg game for different scenarios of the market size.

Eric [33], Dastidar [34], and Qian [17] have mentioned that in the price Stackelberg game, the supply chain has the second-mover advantage (follower). It can be observed from Table 5 that this is not always the case. When the supply chains have the same market size, or the leader has a smaller market size than the follower, the supply chain has the secondmover advantage.

For a better understanding of the conditions assumed for the relations to be met, the total profits of the centralized and decentralized supply chains are shown in two separate charts for $\alpha_{1}>\alpha_{2}$, all the values of set $Y$, and $\lambda=0.6$. According to Figure 1 , the leading chain obtains more profits than the following chain for all values of $\mu$ in the centralized structure. However, the leader obtains lower profits than the follower for the values of $\mu>0.38$ in the decentralized structure (Con.22).

Result 5.7. Now we consider the effect of the presence of a leader in the market. According to the resultant price and profit relations for different scenarios of the market size, the effect of presence of a leader in the market in three cases $\alpha_{1}=\alpha_{2}, \alpha_{1}<\alpha_{2}$, and $\alpha_{1}>\alpha_{2}$ is shown in Tables 9, 10 , and 11, respectively (these tables appear in Appendix C).

The price and profit relations and the necessary conditions are indicated in $\{$.$\} in all the three tables.$

Table 6. Advantage of the mover in the Stackelberg game.

\begin{tabular}{lcccc}
\hline & & \multicolumn{3}{c}{ Market size } \\
\cline { 3 - 5 } & & $\boldsymbol{\alpha}_{\mathbf{1}}=\boldsymbol{\alpha}_{\mathbf{2}}$ & $\boldsymbol{\alpha}_{\mathbf{1}}<\boldsymbol{\alpha}_{\mathbf{2}}$ & $\boldsymbol{\alpha}_{\mathbf{1}}>\boldsymbol{\alpha}_{\mathbf{2}}$ \\
\hline Supply-chain structure & CC & Second mover & Second mover & First mover \\
& DD & Second mover & Second mover & Second mover or first mover \\
\hline
\end{tabular}
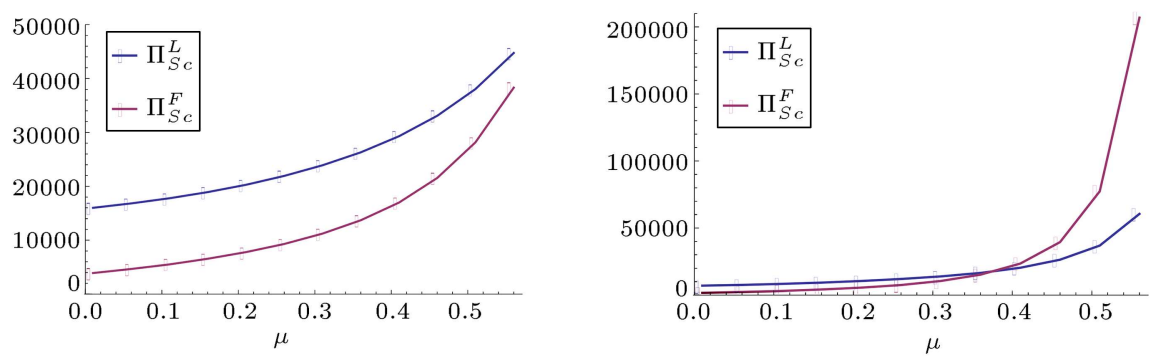

Figure 1. Changes in profit with respect to the competition parameters for $\alpha_{1}>\alpha_{2}$. 
Table 7. Effect of imbalance of market power on profit and decision variables $\left(\alpha_{1}=\alpha_{2}\right)$.

\begin{tabular}{cccc}
\hline $\begin{array}{c}\text { Structure } \\
\text { of supply- } \\
\text { chains }\end{array}$ & Price (non.) & Profit of members (con.) & Profit (con.) \\
\hline $\begin{array}{c}\text { Both } \\
\text { centralized }\end{array}$ & $p_{R}<p_{R}^{F}<p_{R}^{L}\{\forall \lambda, \mu \in \mathrm{X}\}$ & - & $\Pi_{S c}<\Pi_{S c}^{L}<\Pi_{S c}^{F}\{\forall \lambda, \mu \in \mathrm{X}\}$ \\
\hline & $p_{R}^{F}<p_{R}<p_{R}^{L}\{$ Con.3 $\}$ & $\Pi_{R}^{L}<\Pi_{R}<\Pi_{R}^{F}\{\forall \lambda, \mu \in \mathrm{X}\}$ & $\Pi_{S c}^{L}<\Pi_{S c}<\Pi_{S c}^{F}\{\forall \lambda, \mu \in \mathrm{X}\}$ \\
& $p_{R}<p_{R}^{F}<p_{R}^{L}\left\{(\text { Con.3 })^{c}\right\}$ & & \\
Both & $w_{D}^{F}<w_{D}<w_{D}^{L}\left\{(\text { Con.4 })^{c}\right\}$ & $\Pi_{D}^{L}<\Pi_{D}<\Pi_{D}^{F}\{\forall \lambda, \mu \in \mathrm{X}\}$ \\
decentralized & $w_{D}^{F}<w_{D}^{L}<w_{D}\{$ Con.4 $\}$ & \\
& $w_{M}^{F}<w_{M}<w_{M}^{L}\left\{(\text { Con. } 5)^{c}\right\}$ & $\Pi_{M}^{L}<\Pi_{M}<\Pi_{M}^{F}\{\forall \lambda, \mu \in \mathrm{X}\}$ & \\
& $w_{M}^{F}<w_{M}^{L}<w_{M}\{$ Con.5 $\}$ & & \\
\hline
\end{tabular}

Note: $p_{R}$ : Retailer price in a market without leader; $p_{R}^{L}$ : Retailer price of leader chain; $p_{R}^{F}$ : Retailer price of follower chain; $\Pi_{R}$ : Profit of retailer in a market without leade; $\Pi_{R}^{L}$ : Profit of retailer in leader chain; $\Pi_{R}^{F}$ : Profit of retailer in follower chain.

Table 8. Effect of imbalance of market power on profit and decision variables $\left(\alpha_{1}<\alpha_{2}\right)$.

\begin{tabular}{|c|c|c|c|}
\hline $\begin{array}{l}\text { Structure of } \\
\text { supply-chains }\end{array}$ & Price & $\begin{array}{l}\text { Profit of supply } \\
\text { chain members }\end{array}$ & Total profit of supply chain \\
\hline CC structure & $\begin{array}{c}p_{R 1}<p_{R}^{L}<p_{R}^{F}\{\forall \lambda, \mu \in X\} \\
p_{R 2}<p_{R}^{L}<p_{R}^{F}\{\text { Con. } 1\} \\
p_{R}^{L}<p_{R 2}<p_{R}^{F}\left\{(\text { Con. } 1)^{c}\right\}\end{array}$ & - & $\begin{array}{l}\Pi_{S c 1}<\Pi_{S c}^{L}<\Pi_{S c}^{F}\{\forall \lambda, \mu \in X\} \\
\Pi_{S c}^{L}<\Pi_{S c 2}<\Pi_{S c}^{F}\{\forall \lambda, \mu \in X\}\end{array}$ \\
\hline DD Structure & $\begin{array}{c}p_{R}^{F}<p_{R 1}<p_{R}^{L}\{\text { Con. } 8\} \\
p_{R 1}<p_{R}^{F}<p_{R}^{L}\left\{(\text { Con. } 8)^{c} \cap \text { Con. } 21\right\} \\
p_{R 1}<p_{R}^{L}<p_{R}^{F}\left\{(\text { Con. } 8)^{c} \cap(\text { Con. } 21)^{c}\right\} \\
p_{R}^{L}<p_{R}^{F}<p_{R 2}\{\text { Con. } 6\} \\
p_{R 2}<p_{R}^{F}<p_{R}^{L}\{\text { Con. } 21\} \\
p_{R 2}<p_{R}^{L}<p_{R}^{F}\left\{\text { Con. } 7 \cap(\text { Con. } 21)^{c}\right\} \\
p_{R}^{L}<p_{R 2}<p_{R}^{F}\left\{(\text { Con. } 6)^{c} \cap(\text { Con. } 7)^{c}\right\} \\
w_{D}^{F}<w_{D}^{L}<w_{D 1}\{\text { Con. } 9\} \\
w_{D}^{F}<w_{D 1}<w_{D}^{L}\left\{(\text { Con. } 9)^{c} \cap \text { Con. } 10\right\} \\
w_{D 1}<w_{D}^{F}<w_{D}^{L}\left\{(\text { Con. } 10)^{c} \cap \text { Con. } 21\right\} \\
w_{D 1}<w_{D}^{L}<w_{D}^{F}\left\{(\text { Con. } 10)^{c} \cap(\text { Con. } 21)^{c}\right\} \\
w_{D}^{L}<w_{D}^{F}<w_{D 2}\left\{(\text { Con. } 21)^{c}\right\} \\
w_{D}^{F}<w_{D}^{L}<w_{D 2}\{\text { Con. } 21\} \\
w_{M}^{L}<w_{M}^{F}<w_{M 1}\left\{\text { Con. } 12 \cap(\text { Con. } 21)^{c}\right\} \\
w_{M}^{F}<w_{M}^{L}<w_{M 1}\{\text { Con. } 21\} \\
w_{M}^{L}<w_{M 1}<w_{M}^{F}\left\{\text { Con. } 11 \cap(\text { Con. } 12)^{c}\right\} \\
w_{M 1}<w_{M}^{L}<w_{M}^{F}\left\{(\text { Con. } 11)^{c}\right\} \\
w_{M}^{L}<w_{M}^{F}<w_{M 2}\left\{(\text { Con. } 21)^{c}\right\} \\
w_{M}^{F}<w_{M}^{L}<w_{M 2}\{\text { Con. } 21\}\end{array}$ & 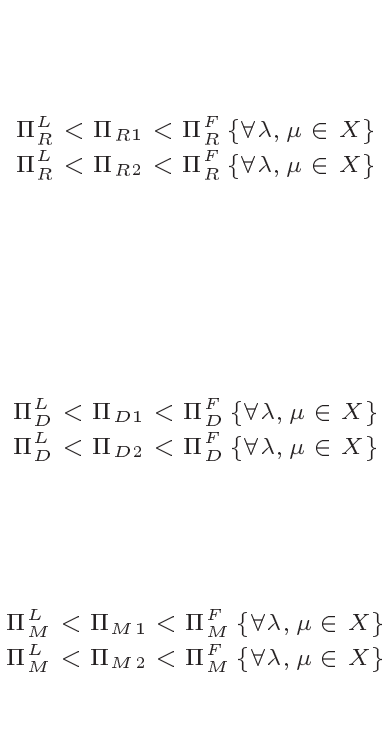 & $\begin{array}{l}\Pi_{S c}^{L}<\Pi_{S c 1}<\Pi_{S c}^{F}\{\forall \lambda, \mu \in X\} \\
\Pi_{S c}^{L}<\Pi_{S c 2}<\Pi_{S c}^{F}\{\forall \lambda, \mu \in X\}\end{array}$ \\
\hline
\end{tabular}

The following points can be inferred from Tables 7, 8, and 9:

1. In the $\mathrm{CC}$ structure, a chain with a larger market size offers a higher price and gains a higher profit in both Nash and Stackelberg scenarios. However, a chain that sells its products at a higher price gains lower profits when $\alpha_{1}=\alpha_{2}$.
2. In the DD structure, the profits of the leading and following chains are regarded as the lower and upper bounds, respectively, of the profits of decentralized chains in the Nash scenario where $\alpha_{1}=\alpha_{2}$ and $\alpha_{1}<\alpha_{2}$; however, there are three cases where $\alpha_{1}>$ $\alpha_{2}$ :

$\Pi_{S c 2}<\Pi_{S c}^{F}<\Pi_{S c}^{L}<\Pi_{S c 1}\{$ Con. 22$\}$, 
Table 9. Effect of imbalance of market power on profit and decision variables $\left(\alpha_{1}>\alpha_{2}\right)$.

\begin{tabular}{|c|c|c|c|}
\hline $\begin{array}{l}\text { Structure } \\
\text { of supply- } \\
\text { chains }\end{array}$ & Price & $\begin{array}{l}\text { Profits of the supply } \\
\text { chain members }\end{array}$ & $\begin{array}{l}\text { Total profit of the } \\
\text { supply chain }\end{array}$ \\
\hline $\mathrm{CC}$ structure & $\begin{array}{c}p_{R 1}<p_{R}^{F}<p_{R}^{L}\{\text { Con. } 2\} \\
p_{R}^{F}<p_{R 1}<p_{R}^{L}\left\{(\text { Con. } 2)^{c}\right\} \\
p_{R 2}<p_{R}^{F}<p_{R}^{L}\{\forall \lambda, \mu \in X\}\end{array}$ & - & $\begin{array}{l}\Pi_{S c}^{F}<\Pi_{S c 1}<\Pi_{S c}^{L}\{\forall \lambda, \mu \in X\} \\
\Pi_{S c 2}<\Pi_{S c}^{F}<\Pi_{S c}^{L}\{\forall \lambda, \mu \in X\}\end{array}$ \\
\hline \multirow{3}{*}{$\begin{array}{c}\mathrm{DD} \\
\text { structure }\end{array}$} & $\begin{array}{c}p_{R}^{F}<p_{R 1}<p_{R}^{L}\{\forall \lambda, \mu \in X\} \\
p_{R}^{F}<p_{R 2}<p_{R}^{L}\{\text { Con.13\} } \\
p_{R 2}<p_{R}^{F}<p_{R}^{L}\left\{(\text { Con. } 13)^{c}\right\}\end{array}$ & 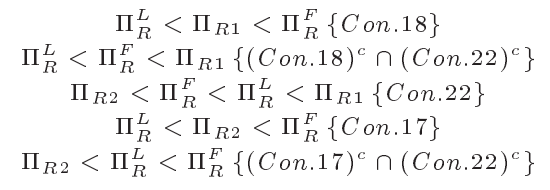 & \multirow{3}{*}{ 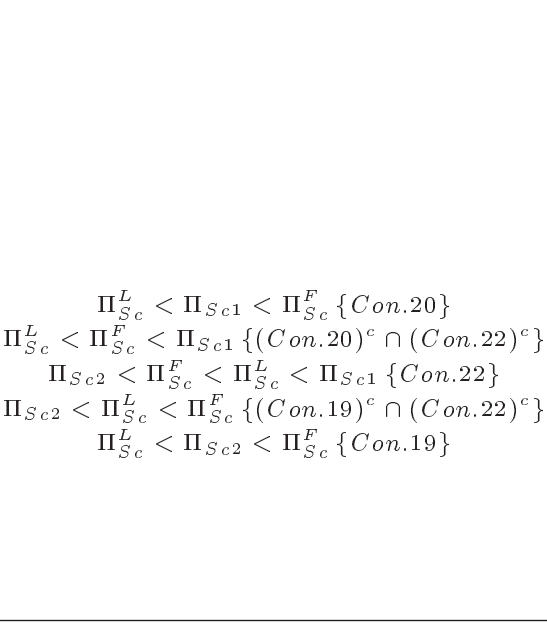 } \\
\hline & $\begin{array}{c}w_{D}^{F}<w_{D 1}<w_{D}^{L}\left\{(\text { Con.14 })^{c}\right\} \\
w_{D}^{F}<w_{D}^{L}<w_{D 1}\{\text { Con. } 14\} \\
w_{D}^{F}<w_{D}^{L}<w_{D 2}\{\text { Con.15\} }\} \\
w_{D}^{F}<w_{D 2}<w_{D}^{L}\left\{(\text { Con. } 15)^{c}\right\}\end{array}$ & $\begin{array}{c}\Pi_{D}^{L}<\Pi_{D 1}<\Pi_{D}^{F}\{\{\text { Con. } 18\} \\
\Pi_{D}^{L}<\Pi_{D}^{F}<\Pi_{D 1}\left\{(\text { Con.18 })^{c} \cap(\text { Con. } 22)^{c}\right\} \\
\Pi_{D}^{F}<\Pi_{D}^{L}<\Pi_{D 1}, \Pi_{D 2}\{\text { Con. } 22\} \\
\Pi_{D}^{L}<\Pi_{D 2}<\Pi_{D}^{F}\{\text { Con. } 17\} \\
\Pi_{D}^{L}<\Pi_{D}^{F}<\Pi_{D 2}\left\{(\text { Con.17 })^{c} \cap(\text { Con. } 22)^{c}\right\}\end{array}$ & \\
\hline & $\begin{array}{c}w_{M}^{F}<w_{M 1}<w_{M}^{L}\left\{(\text { Con.16 })^{c}\right\} \\
w_{M}^{F}<w_{M}^{L}<w_{M 1}\{\text { Con. } 16\} \\
w_{M}^{F}<w_{M}^{L}<w_{M 2}\{\text { Con. } 10\} \\
w_{M}^{F}<w_{M 2}<w_{M}^{L}\left\{(\text { Con. } 10)^{c}\right\}\end{array}$ & $\begin{array}{c}\Pi_{M}^{L}<\Pi_{M 1}<\Pi_{M}^{F}\{\text { Con.18 }\} \\
\Pi_{M}^{L}<\Pi_{M}^{F}<\Pi_{M 1}\left\{(\text { Con.18 })^{c} \cap(\text { Con.22 })^{c}\right\} \\
\Pi_{M}^{F}<\Pi_{M}^{L}<\Pi_{M 1}, \Pi_{M 2}\{\text { Con. } 22\} \\
\Pi_{M}^{L}<\Pi_{M 2}<\Pi_{M}^{F}\{\text { Con.17\} } \\
\Pi_{D}^{L}<\Pi_{D}^{F}<\Pi_{D 2}\left\{(\text { Con.17 })^{c} \cap(\text { Con. } 22)^{c}\right\}\end{array}$ & \\
\hline
\end{tabular}

$\Pi_{S c 2}<\Pi_{S c}^{L}<\Pi_{S c}^{F}<\Pi_{S c 1}\left\{(\text { Con.19 })^{c} \cap(\text { Con.22 })^{c}\right\}$

$\Pi_{S c}^{L}<\Pi_{S c 1}, \Pi_{S c 2}<\Pi_{S c}^{F}\{$ Con.20\}.

We have Con.20 $\cap$ Con.19= Con.20 and $(\text { Con.19 })^{c} \cap(\text { Con.22 })^{c} \cap(\text { Con.20 })^{c}=(\text { Con.19 })^{c} \cap$ $(\text { Con.22) })^{c}$.

3. In the DD structure, the leading chain never obtains higher profits than in the Nash scenario in different cases of market size, but the follower always obtains higher profit.

Result 8. Here managerial insights are considered. A general conclusion is drawn in terms of the best supply chain decisions under various conditions (Table 10). In other words, the best power structure in the market is selected to obtain the greatest profit according to the parameters and structure of the supply chain. Therefore, the following table is used as a solution for managerial decisions under various conditions in a duopoly market with two competitive supply chains:

- For different situations of the market size, the following conditions hold. For example, if the centralized chains function in the market power balance mode (as shown in Table 6), offering a new product in the market will cause both chains to benefit from the process. In such a market, both chains will benefit if either of them becomes a leader.

In the DD structure, it is better for both chains to make simultaneous decisions;
- Finally, the last column shows which of the movers, first or second, can obtain a higher profit than its competitor in the presence of a leader in the market.

\section{Conclusion and future works}

We investigated a competitive model between two supply chains with three echelons. Four scenarios were developed based on the power structures of the two chains in the market. For cases of a power balance mode between the two chains in the market, two scenarios were developed, which were dependent on the structures of the two chains (centralized or decentralized). The other two scenarios captured the market conditions with imbalanced power between the chains. In fact, the model attempted to analyze the impact of market power imbalance on the prices and profits of the supply chains under different conditions of market size for supply chains with the same structure.

By investigating different scenarios (combination of the structures of the supply chains and the power structure between them), we achieved novel results, which had not been achieved in the previous research through investigation of only one of these at a time.

The significant novel findings of the research are shown in Tables 4, 6, and 10. The results demonstrated that having a centralized structure was the only case in which the presence of a leader is beneficial to both of the supply chains for different market size conditions. 
Table 10. Managerial decisions under various conditions.

\begin{tabular}{|c|c|c|c|}
\hline $\begin{array}{l}\text { Supply-chain } \\
\text { structure }\end{array}$ & $\begin{array}{l}\text { Supply chain } \\
\text { conditions }\end{array}$ & Appropriate strategy for obtaining maximal profit & $\begin{array}{c}\text { Mover } \\
\text { with } \\
\text { advantage }\end{array}$ \\
\hline \multirow{3}{*}{$\begin{array}{c}\text { Both } \\
\text { centralized }\end{array}$} & $\alpha_{1}=\alpha_{2}$ & $\begin{array}{l}\text { Presence of a leader in the market: } \\
\text { When there is a leader in the market, both chains gain greater profit than in the power } \\
\text { balance mode in the market. } \\
\text { The chain that functions as the follower gains higher profit than the leader. }\end{array}$ & $\begin{array}{l}\text { Second } \\
\text { mover }\end{array}$ \\
\hline & $\alpha_{1}<\alpha_{2}$ & $\begin{array}{l}\text { The power imbalance mode of the market is beneficial to the chain with a smaller market } \\
\text { size (the first chain) because it can obtain higher profits if it functions as a leader than when } \\
\text { there is no leader in the market. } \\
\text { Presence of a leader in the market is beneficial to the chain with a greater market size (the } \\
\text { second chain) because it gains higher profit than in the Nash scenario. } \\
\text { Finally, presence of a leader in the market is beneficial to both chains. }\end{array}$ & $\begin{array}{l}\text { Second } \\
\text { mover }\end{array}$ \\
\hline & $\alpha_{1}>\alpha_{2}$ & $\begin{array}{l}\text { The chain with a larger market size (the first chain) benefits from the power imbalance } \\
\text { mode because the leadership leads to more profit than in the Nash mode. } \\
\text { The chain with a smaller market size (the second chain) benefits from the power imbalance } \\
\text { mode because it can obtain more profit in this market than in a market without a leader. } \\
\text { Finally, presence of a leader benefits both chains in the market. }\end{array}$ & $\begin{array}{l}\text { First } \\
\text { mover }\end{array}$ \\
\hline \multirow{3}{*}{ Both decentralized } & $\alpha_{1}=\alpha_{2}$ & $\begin{array}{l}\text { Absence of a leader in the market. } \\
\text { In a market with a leader, the following chain obtains greater profit than in the power } \\
\text { balance mode, while the leading chain earns less profit. Presence of a leader in the market } \\
\text { is in favor of the chain acting as the follower. Hence, it is not beneficial to either of the } \\
\text { supply chains. }\end{array}$ & $\begin{array}{l}\text { Second } \\
\text { mover }\end{array}$ \\
\hline & $\alpha_{1}<\alpha_{2}$ & $\begin{array}{l}\text { The first chain with a smaller market size, which functions as the leader, obtains lower } \\
\text { profits than in the Nash scenario. Therefore, it is not beneficial to this chain to be a leader. } \\
\text { However, it is beneficial to the second chain with a greater market size to be a follower and } \\
\text { obtain more profits than in the Nash scenario. } \\
\text { Therefore, presence of a leader is not advised in such conditions because it is beneficial } \\
\text { only to the following chain. However, the first chain with a greater market size loses much } \\
\text { in the market despite being a leader. }\end{array}$ & $\begin{array}{l}\text { Second } \\
\text { mover }\end{array}$ \\
\hline & $\alpha_{1}>\alpha_{2}$ & $\begin{array}{l}\text { Supply chain with a larger market size. In different conditions and combinations of } \\
\text { competitive parameters, it is not favorable for this chain to act as a leader. This chain } \\
\text { obtains more profits in a market without a leader. } \\
\text { Supply chain with a smaller market size. In different combinations of competitive } \\
\text { parameters, it can be stated that presence of a leader is beneficial to this chain. Unlike the } \\
\text { former chain, this one can obtain more profits than in the Nash scenario if it functions as } \\
\text { the following chain with a smaller size. } \\
\text { Therefore, the power imbalance mode is beneficial only to the chain with a smaller market } \\
\text { size, which acts as the follower. }\end{array}$ & $\begin{array}{l}\text { Second } \\
\text { mover or } \\
\text { first } \\
\text { mover }\end{array}$ \\
\hline
\end{tabular}

Besides, in the price Stackelberg game, the supply chain does not always have a second mover.

Eventually, the following conditions hold regarding the effect of the relations between the market sizes of the supply chains on profit:

- If the chains are of the same size or the chain with the smaller-sized market functions as the leader, the following chain will obtain maximal profit regardless of chain structure (compared with the leading chain and supply chains in the Nash scenario). The presence of the leader is beneficial to a centralized leading chain, but not to a decentralized one; 
- If a chain with a larger market size functions as a leader in the market power imbalance mode, the presence of a leader will benefit the following chain with a smaller market size under any conditions regardless of chain structure, but maximal profit will not necessarily be obtained. The presence of the leader is beneficial to a centralized leader chain, but not to a decentralized one;

- The presence of the leader will be beneficial to both chains if they are centralized regardless of their market sizes. In the DD structure, however, the presence of the leader is favorable to the following chain and disadvantageous to the leading chain.

The conclusions were drawn based on the assumptions made for this competitive model. Therefore, the model can be developed by several methods. Firstly, price was taken into account as the competition parameter, while other factors can be considered as well. Demand uncertainty is another aspect of the model. Secondly, we assumed in this paper that all chain members have symmetric information on demand, while in other models, asymmetric information can be developed for all members. Further studies are required to investigate different power structures in the supply chain. Also, more members can be considered at each level in future studies. Finally, we assumed that all members in both chains were risk-neutral. In future studies, risk-averse members can be considered.

\section{References}

1. Jaber, M.Y. and Goyal, S.K. "Coordinating a threelevel supply chain with multiple suppliers, a vendor and multiple buyers", International Journal of Production Economics, 116(1), pp. 95-103 (2008).

2. Nash, J.F. "The bargaining game", Econometrica, 18(2), pp. 155-162 (1950).

3. Heydari, J., Govindan, K., and Aslani, A. "Pricing and greening decisions in a three-tier dual channel supply chain", International Journal of Production Economics, 217, pp. 185-196 (2019).

4. Lan, Y., Li, Y., and Papier, F. "Competition and coordination in a three-tier supply chain with differentiated channels", European Journal of Operational Research, 269(3), pp. 870-882 (2018).

5. Modak, N.M., Panda, S., and Sana, S.S. "Threeechelon supply chain coordination considering duopolistic retailers with perfect quality products", International Journal of Production Economics, 182, pp. 564-578 (2016).

6. Naimi Sadigh, A., Chaharsooghi, S.K., and Sheikhmohammady, M. "Game-theoretic analysis of coordinating pricing and marketing decisions in a multi- product multi-echelon supply chain", Scientia Iranica, E, 23(3), pp. 1459-1473 (2016).

7. Pan, K., Lai, K.K., Leung, S.C.H., and Xiao, D. "Revenue-sharing versus wholesale price mechanisms under different channel power structures", European Journal of Operational Research, 203(2), pp. 532-538 (2010).

8. Giri, B.C., Chakraborty, A., and Maiti, T. "Quality and pricing decisions in a two-echelon supply chain under multi-manufacturer competition", The International Journal of Advanced Manufacturing Technology, 78(9), pp. 1927-1941 (2015).

9. Wang, L., Song, H., and Wang, Y. "Pricing and service decisions of complementary products in a dual-channel supply chain", Computers \& Industrial Engineering, 105, pp. 223-233 (2017).

10. Mokhlesian, M. and Zegordi, S.H. "Pricing and advertising decisions in a dominant-retailer supply chain: A multi-follower bi-level programming approach", Scientia Iranica, E, 25(4), pp. 2254-2266 (2018).

11. Li, W. and Chen, J. "Pricing and quality competition in a brand-differentiated supply chain", International Journal of Production Economics, 202, pp. 97-108 (2018).

12. Giri, B.C. and Dey, S.K. "Game theoretic analysis of a closed-loop supply chain with backup supplier under dual channel recycling", Computers and Industrial Engineering, 129, pp. 179-191 (2019). doi.org/10.1016/j.cie.2019.01.035

13. Zheng, X., Liu, Z., Li, K.W., Huang, J., and Chen, J. "Cooperative game approaches to coordinating a three-echelon closed-loop supply chain with fairness concerns", International Journal of Production Economics, 212, pp. 92-110 (2019). doi.org/10.1016/j.ijpe.2019.01.011

14. McGuire, T.W. and Staelin, R. "An Industry equilibrium analysis of downstream vertical integration", Marketing Science, 2(2), pp. 161-191 (1983).

15. Moorthy, K.S. "Strategic decentralization in channels", Marketing Science, 7(4), pp. 335-355 (1988).

16. Boyaci, T. and Gallego, G. "Supply chain coordination in a market with customer service competition", Production and Operations Management, 13(1), pp. 3-22 (2004).

17. Qian, Y. "Competitive parallel distribution channels with move sequence", Journal of Systems Science and Systems Engineering, 15(1), pp. 114-123 (2006).

18. Xiao, T. and Yang, D. "Price and service competition of supply chains with risk-averse retailers under demand uncertainty", International Journal of Production Economics, 114(1), pp. 187-200 (2008).

19. Wu, D., Baron, O., and Berman, O. "Bargaining in competing supply chains with uncertainty", European Journal of Operational Research, 197(2), pp. 548-556 (2009). 
20. Anderson, E.J. and Bao, Y. "Price competition with integrated and decentralized supply chains", European Journal of Operational Research, 200(1), pp. 227-234 (2010).

21. Li, B.-X., Zhou, Y.-W., Li, J.-Z., and Zhou, S.-P. "Contract choice game of supply chain competition at both manufacturer and retailer levels", International Journal of Production Economics, 143(1), pp. 188-197 (2013).

22. Mahmoodi, A. and Eshghi, K. "Price competition in duopoly supply chains with stochastic demand", Journal of Manufacturing Systems, 33(4), pp. 604-612 (2014).

23. Amin-Naseri, M.R. and Azari Khojasteh, M. "Price competition between two leader-follower supply chains with risk-averse retailers under demand uncertainty", The International Journal of Advanced Manufacturing Technology, 79(1), pp. 377-393 (2015).

24. Baron, O., Berman, O., and Wu, D. "Bargaining within the supply chain and its implications to in an industry", Decision Sciences, 47(2), pp. 193-218 (2016).

25. Zheng, Y., Shu, T., Wang, S., Chen, S., Keung Lai, K., and Gan, L. "Analysis of product return rate and price competition in two supply chains", Operational Research, 18, pp. 469-496 (2018).

26. Hafezalkotob, A., Borhani, S., and Zamani, S. "Development of a Cournot-oligopoly model for competition of multi-product supply chains under government supervision", Scientia Iranica, E, 24(3), pp. 1519-1532 (2017).

27. Taleizadeh, A.A. and Sadeghi, R. "Pricing strategies in the competitive reverse supply chains with traditional and e-channels: A game theoretic approach", International Journal of Production Economics, 215, pp. 48-60 (2019). doi.org/10.1016/j.ijpe.2018.06.011

28. Ha, A.Y. and Tong, S. "Contracting and information sharing under supply chain competition", Management Science, 54(4), pp. 701-715 (2008).

29. Wu, D. "Coordination of competing supply chains with news-vendor and buyback contract", International Journal of Production Economics, 144(1), pp. 1-13 (2013).

30. Li, X. and Li, Y. "Chain-to-chain competition on product sustainability", Journal of Cleaner Production, 112(3), pp. 2058-2065 (2014).

31. Lu, J.-C., Tsao, Y.-C., and Charoensiriwath, C. "Competition under manufacturer service and retail price", Economic Modelling, 28(3), pp. 1256-1264 (2011).

32. Tsay, A.A. and Agrawal, N. "Channel dynamics under price and service competition", Manufacturing \& Service Operations Management, 2(4), pp. 372-391 (2000).

33. Eric, R., Games and Information: An Introduction to Game Theory, Basil Blackwell, Cambridge (1994).

34. Dastidar, K.G. "On Stackelberg games in a homogeneous product market", European Economic Review, 48(3), pp. 549-562 (2004).

\section{Appendix A. Parameters for the Nash and Stackelberg games}

$$
\begin{aligned}
& A_{1}=\frac{1}{\left(16 \lambda^{4}-17 \lambda^{2} \mu^{2}+4 \mu^{4}\right)} \\
& A_{2}= \\
& \quad \frac{1}{\left(256 \lambda^{8}-580 \lambda^{6} \mu^{2}+456 \lambda^{4} \mu^{4}-145 \lambda^{2} \mu^{6}+16 \mu^{8}\right)} \\
& A_{3}=2 \lambda\left(64 \lambda^{6}-90 \lambda^{4} \mu^{2}+38 \lambda^{2} \mu^{4}-5 \mu^{6}\right) \\
& A_{4}=\mu\left(112 \lambda^{6}-154 \lambda^{4} \mu^{2}+63 \lambda^{2} \mu^{4}-8 \mu^{6}\right) \\
& A_{6}=4 \lambda\left(4 \lambda^{2}-3 \mu^{2}\right)\left(3 \lambda^{2}-\mu^{2}\right)\left(\frac{A_{3}}{2 \lambda}\right), \\
& A_{5}=c_{M}\left(8 \lambda^{4}-9 \lambda^{2} \mu^{2}+2 \mu^{4}\right)\left(16 \lambda^{4}+2 \lambda^{3} \mu\right. \\
& \left.-18 \lambda^{2} \mu^{2}-\lambda \mu^{3}+4 \mu^{4}\right) \\
& A_{7}=-2 \mu\left(-3 \lambda^{2}+\mu^{2}\right)\left(-4 \lambda^{2}+3 \mu^{2}\right)\left(\frac{-A_{4}}{\mu}\right), \\
& A_{8}=A_{5}\left(4 \lambda^{2}+\lambda \mu-2 \mu^{2}\right)\left(2 \lambda^{2}-\mu^{2}\right) .
\end{aligned}
$$

\section{Appendix B. Proving the theorems}

Proof of Theorem 4.1: The relations are proven according to Table 3 .

Relations (1) and (2):

$$
p_{R 1}^{S}-p_{R 2}^{N}=p_{R 1}^{S}-p_{R 1}^{N}=\frac{\mu^{2}\left(-\lambda c_{M}+\alpha+\mu c_{M}\right)}{2(2 \lambda-\mu)\left(2 \lambda^{2}-\mu^{2}\right)} .
$$

If $\alpha>c_{M}(\lambda-\mu)(*)$ and $\lambda>\mu$, then $p_{R 1}^{S}-p_{R 1}^{N}>0$; therefore, $p_{R 1}^{S}>p_{R 1}^{N}$.

Relations (3) and (4):

$$
p_{R 2}^{S}-p_{R 1}^{N}=p_{R 2}^{S}-p_{R 2}^{N}=\frac{\mu^{3}\left(-\lambda c_{M}+\alpha+\mu c_{M}\right)}{4 \lambda(2 \lambda-\mu)\left(2 \lambda^{2}-\mu^{2}\right)} .
$$

According to $\left(^{*}\right)$ and $\lambda>\mu$, the above relation is always positive; therefore, $p_{R 2}^{S}>p_{R 2}^{N}$.

Relations (5) and (6):

$$
\Pi_{1}^{S}-\Pi_{2}^{N}=\Pi_{1}^{S}-\Pi_{1}^{N}=\frac{\mu^{4}\left(-\lambda c_{M}+\alpha+\mu c_{M}\right)^{2}}{8(-2 \lambda+\mu)^{2}\left(2 \lambda^{3}-\lambda \mu^{2}\right)} .
$$

Since $\lambda>\mu, \lambda^{2}>\mu^{2}$; therefore, $\lambda^{3}>\lambda \mu^{2}$ and $2 \lambda^{3}>$ $\lambda \mu^{2}$. It can be concluded that this relation is always 
positive.

Relations (7) and (8):

$$
\begin{aligned}
\Pi_{2}^{S} & -\Pi_{1}^{N}=\Pi_{2}^{S}-\Pi_{2}^{N} \\
& =\frac{\left(-\lambda c_{M}+\alpha+\mu c_{M}\right)^{2}\left(16 \lambda^{3} \mu^{3}-8 \lambda \mu^{5}+\mu^{6}\right)}{16 \lambda(-2 \lambda+\mu)^{2}\left(-2 \lambda^{2}+\mu^{2}\right)^{2}}
\end{aligned}
$$

Because $16 \lambda^{3} \mu^{3}-8 \lambda \mu^{5}+\mu^{6}=8 \lambda \mu^{3}\left(2 \lambda^{2}-\mu^{2}\right)+\mu^{6}>0$, $\Pi_{2}^{S}>\Pi_{2}^{N}$ and $\Pi_{2}^{S}>\Pi_{1}^{N}$.

$$
\begin{aligned}
\lambda \alpha_{1} & +\lambda\left(\alpha_{1}+\mu c_{M}\right)+\mu\left(\alpha_{2}+\mu c_{M}\right)>\lambda \alpha_{1} \\
& +\lambda\left(\lambda c_{M}\right)+\mu\left(\lambda c_{M}\right)=\lambda\left(\alpha_{1}+\mu c_{M}+\lambda c_{M}\right) \\
& >\lambda\left(\lambda c_{M}+\lambda c_{M}\right)=2 \lambda^{2} c_{M} .
\end{aligned}
$$

\section{Proof of Theorem 4.2:}

1) We have $8 \lambda^{4}-6 \lambda^{2} \mu^{2}+\mu^{4}=2 \lambda^{2}\left(4 \lambda^{2}-3 \mu^{2}\right)+\mu^{4}>$ 0 . Now, we have to show that $\left(2 \alpha_{1}+\mu c_{M}\right)+$ $\mu\left(\alpha_{2}+\mu c_{M}\right)>2 \lambda^{2} c_{M}$. According to $\left(^{*}\right)$ :

$$
\begin{aligned}
\lambda \alpha_{1} & +\lambda\left(\alpha_{1}+\mu c_{M}\right)+\mu\left(\alpha_{2}+\mu c_{M}\right)>\lambda \alpha_{1} \\
& +\lambda\left(\lambda c_{M}\right)+\mu\left(\lambda c_{M}\right)=\lambda\left(\alpha_{1}+\mu c_{M}+\lambda c_{M}\right) \\
& >\lambda\left(\lambda c_{M}+\lambda c_{M}\right)=2 \lambda^{2} c_{M} .
\end{aligned}
$$

Therefore, $p_{R 1}^{S}>p_{R 1}^{N}$.

2,3) Given (**), always $p_{R 2}^{S}>p_{R 2}^{N}$ and $\Pi_{1}^{S}>\Pi_{1}^{N}$.

4) We show that $\Pi_{2}^{S}-\Pi_{2}^{N}>0$; therefore, the above relation is written by the equation shown in Box B.I. Therefore:

$$
\begin{aligned}
& \mid 4 \lambda^{2}\left(\lambda c_{M}-\alpha_{2}\right)-2 \lambda \mu\left(\lambda c_{M}+\alpha_{1}\right) \\
& \quad+\mu^{2}\left(-3 \lambda c_{M}+\alpha_{2}\right)+\mu^{3} c_{M}||-4 \lambda^{2}+\mu^{2} \mid \\
& >4 \lambda\left|-2 \lambda^{2} c_{M}+\mu\left(\alpha_{1}+\mu c_{M}\right)+\lambda\left(2 \alpha_{2}+\mu c_{M}\right)\right| \\
& \left|-2 \lambda^{2}+\mu^{2}\right| .
\end{aligned}
$$

Now, the sign of the expressions is specified.

$$
\begin{aligned}
& 4 \lambda^{2}\left(\lambda c_{M}-\alpha_{2}\right)-2 \lambda \mu\left(\lambda c_{M}+\alpha_{1}\right) \\
& +\mu^{2}\left(-3 \lambda c_{M}+\alpha_{2}\right)+\mu^{3} c_{M}=4 \lambda^{2}\left(\lambda c_{M}-\alpha_{2}\right) \\
& -2 \lambda \mu\left(\lambda c_{M}+\alpha_{1}\right)-\mu^{2}\left(-\alpha_{2}+\lambda c_{M}+2 \lambda c_{M}\right) \\
& +\mu^{3} c_{M}=\left(4 \lambda^{2}-\mu^{2}\right)\left(\lambda c_{M}-\alpha_{2}\right)-2 \mu^{2} \lambda c_{M} \\
& +\mu^{3} c_{M}+2 \lambda \mu\left(-\alpha_{1}-\lambda c_{M}\right)<\mu c_{M}\left(4 \lambda^{2}-\mu^{2}\right) \\
& -2 \mu^{2} \lambda c_{M}+\mu^{3} c_{M}+2 \lambda \mu\left(\mu c_{M}-2 \lambda c_{M}\right) \\
& =c_{M}\left(4 \lambda^{2} \mu-\mu^{3}-2 \mu^{2} \lambda+\mu^{3}+2 \mu^{2} \lambda-4 \lambda^{2} \mu\right) \\
& =0
\end{aligned}
$$

and:

$$
\begin{aligned}
& -2 \lambda^{2} c_{M}+\mu\left(\alpha_{1}+\mu c_{M}\right)+\lambda\left(\alpha_{2}+\alpha_{2}+\mu c_{M}\right) \\
& >-2 \lambda^{2} c_{M}+\lambda \mu c_{M}+\lambda^{2} c_{M}+\lambda \alpha_{2} \\
& =c_{M}\left(-\lambda^{2}+\lambda \mu\right)+\lambda \alpha_{2}=\lambda\left(\alpha_{2}-c_{M}(\lambda-\mu)\right)
\end{aligned}
$$

$>0$.

For proving the above relations, $(*)$ is used. The other expressions are negative because $\lambda>\mu$. Therefore:

$$
\begin{aligned}
& \left(4 \lambda^{2}\left(\lambda c_{M}-\alpha_{2}\right)-2 \lambda \mu\left(\lambda c_{M}+\alpha_{1}\right)\right. \\
& \left.+\mu^{2}\left(-3 \lambda c_{M}+\alpha_{2}\right)+\mu^{3} c_{M}\right)\left(-4 \lambda^{2}+\mu^{2}\right) \\
& >4 \lambda\left(-2 \lambda^{2} c_{M}+\mu\left(\mu c_{M}+\alpha_{1}\right)\right. \\
& \left.\quad+\lambda\left(2 \alpha_{2}+\mu c_{M}\right)\right)\left(2 \lambda^{2}-\mu^{2}\right) .
\end{aligned}
$$

This relation is equal to:

$$
\begin{gathered}
\frac{\left(4 \lambda^{2}\left(\lambda c_{M}-\alpha_{2}\right)-2 \lambda \mu\left(\lambda c_{M}+\alpha_{1}\right)+\mu^{2}\left(-3 \lambda c_{M}+\alpha_{2}\right)+\mu^{3} c_{M}\right)^{2}}{16 \lambda\left(-2 \lambda^{2}+\mu^{2}\right)^{2}}> \\
\frac{\lambda\left(-2 \lambda^{2} c_{M}+\mu\left(\alpha_{1}+\mu c_{M}\right)+\lambda\left(2 \alpha_{2}+\mu c_{M}\right)\right)^{2}}{\left(-4 \lambda^{2}+\mu^{2}\right)^{2}}
\end{gathered}
$$




$$
\begin{aligned}
& p_{R 1}^{S}-p_{R 2}^{S}=\frac{7\left(64 \lambda^{2}\left(\alpha_{1}-\alpha_{2}\right)-7 \lambda \mu\left(8 \alpha_{1}-8 \alpha_{2}+c_{M} \mu\right)+7 \mu^{2}\left(\alpha_{2}+c_{M} \mu\right)\right)}{64\left(8 \lambda^{3}-7 \lambda \mu^{2}\right)} \\
& w_{D 1}^{S}-w_{D 2}^{S}=\frac{3\left(64 \lambda^{2}\left(\alpha_{1}-\alpha_{2}\right)-7 \lambda \mu\left(8 \alpha_{1}-8 \alpha_{2}+c_{M} \mu\right)+7 \mu^{2}\left(\alpha_{2}+c_{M} \mu\right)\right)}{32\left(8 \lambda^{3}-7 \lambda \mu^{2}\right)} \\
& w_{M 1}^{S}-w_{M 2}^{S}=\frac{\left.64 \lambda^{2}\left(\alpha_{1}-\alpha_{2}\right)-7 \lambda \mu\left(8 \alpha_{1}-8 \alpha_{2}+c_{M} \mu\right)+7 \mu^{2}\left(\alpha_{2}+c_{M} \mu\right)\right)}{16\left(8 \lambda^{3}-7 \lambda \mu^{2}\right)}
\end{aligned}
$$

Box B.II

$$
\begin{aligned}
& -16 \lambda^{5} c_{M}+\left(16 \alpha_{2}+8 \mu c_{M}\right) \lambda^{4} \\
& +\left(8 \mu \alpha_{1}+16 \mu^{2} c_{M}\right) \lambda^{3} \\
& +\left(-8 \alpha_{2} \mu^{2}-6 \mu^{3} c_{M}\right) \lambda^{2} \\
& +\left(-2 \alpha_{1} \mu^{3}-3 \mu^{4} c_{M}\right) \lambda+\mu^{4}\left(\alpha_{2}+\mu c_{M}\right) \\
& >-16 \lambda^{5} c_{M}+\left(16 \alpha_{2}+8 \mu c_{M}\right) \lambda^{4} \\
& +\left(8 \mu \alpha_{1}+16 \mu^{2} c_{M}\right) \lambda^{3} \\
& +\left(-8 \alpha_{2} \mu^{2}-4 \mu^{3} c_{M}\right) \lambda^{2} \\
& +\left(-4 \alpha_{1} \mu^{3}-4 \mu^{4} c_{M}\right) \lambda .
\end{aligned}
$$

Finally, we have:

$$
\begin{gathered}
-2 \mu^{3} \lambda^{2} c_{M}+\mu^{4}\left(\alpha_{2}+\mu c_{M}\right) \\
>\lambda\left(-2 \alpha_{1} \mu^{3}-\mu^{4} c_{M}\right) .
\end{gathered}
$$

Therefore, we only need to show that:

$$
\begin{array}{r}
-2 \mu^{3} \lambda^{2} c_{M}+\mu^{4}\left(\alpha_{2}+\mu c_{M}\right) \\
-\lambda\left(-2 \alpha_{1} \mu^{3}-\mu^{4} c_{M}\right)>0 .
\end{array}
$$

We have:

$$
\begin{aligned}
& -2 \mu^{3} \lambda^{2} c_{M}+\mu^{4}\left(\alpha_{2}+\mu c_{M}\right)-\lambda\left(-2 \alpha_{1} \mu^{3}-\mu^{4} c_{M}\right) \\
& =\mu^{3}\left(c_{M}\left(\lambda \mu+\mu^{2}-2 \lambda^{2}\right)\right.
\end{aligned}
$$

$$
\begin{aligned}
& \left.+\mu \alpha_{2}+2 \lambda \alpha_{1}\right)>\mu^{3}\left(\lambda \mu c_{M}-\lambda \mu c_{M}\right. \\
& \left.+2 \lambda^{2} c_{M}-2 \lambda^{2} c_{M}\right)=0 .
\end{aligned}
$$

Therefore, $\Pi_{2}^{S}>\Pi_{2}^{N}$.

Proof of Theorem 5.5. We have the relations shown in Box B.II. Due to the similarity of the above relations, only the third relation is evaluated here.

Since $\lambda>\mu$, the denominator is always positive. Therefore, we only need to evaluate the numerator. Since $\lambda>\mu$ and $\alpha_{1}>\alpha_{2}, 64 \lambda^{2}\left(\alpha_{1}-\alpha_{2}\right)-56 \lambda \mu\left(\alpha_{1}-\right.$ $\left.\alpha_{2}\right)>0$ is always true. On the other hand:

$$
\begin{aligned}
& 7 \mu^{2}\left(\alpha_{2}+c_{M} \mu\right)-7 \lambda \mu^{2} c_{M} \\
& =7 \mu^{2}\left(\alpha_{2}+c_{M} \mu-c_{M} \lambda\right) .
\end{aligned}
$$

The expression is always positive according to $\left(^{*}\right)$; therefore, the numerator is always positive. Therefore, $w_{M 1}^{S}>w_{M 2}^{S}$. Thus, $w_{D 1}^{S}>w_{D 2}^{S}$ and $p_{R 1}^{S}>p_{R 2}^{S}$ are also true.

\section{Appendix C}

Table C.1 shows the relations between the profits and sale prices of the supply chains and Table C.2 shows the price and profit relations in the Nash and Stackelberg scenarios for both conditions of equality and inequality of market sizes in the two chains.

\section{Appendix D}

Here a list of the conditions (con.) used in the relations is given in Table D.1.

Table C.1. The price and profit relations of centralized supply chains for different market sizes.

\begin{tabular}{ccc}
\hline & \multicolumn{2}{c}{ Market size of supply chains } \\
\hline Relations of price and profit & $\boldsymbol{\alpha}_{\mathbf{1}}<\boldsymbol{\alpha}_{\mathbf{2}}$ & $\boldsymbol{\alpha}_{\mathbf{1}}>\boldsymbol{\alpha}_{\mathbf{2}}$ \\
\hline$p_{R 1}^{S}>p_{R 2}^{N}$ & $C o n .1$ & $\forall \lambda, \mu \in X$ \\
$p_{R 2}^{S}>p_{R 1}^{N}$ & $\forall \lambda, \mu \in X$ & $C o n .2$ \\
$\Pi_{1}^{S}-\Pi_{2}^{N}$ & $\forall \lambda, \mu \in X: \Pi_{1}^{S}<\Pi_{2}^{N}$ & $\forall \lambda, \mu \in X: \Pi_{1}^{S}>\Pi_{2}^{N}$ \\
$\Pi_{2}^{S}-\Pi_{1}^{N}$ & $\forall \lambda, \mu \in X: \Pi_{2}^{S}>\Pi_{1}^{N}$ & $\forall \lambda, \mu \in X: \Pi_{2}^{S}<\Pi_{1}^{N}$ \\
\hline
\end{tabular}


Table C.2. The relations of price and profit of decentralized supply chains for different market sizes.

\begin{tabular}{|c|c|c|c|c|}
\hline & \multirow{2}{*}{$\begin{array}{c}\text { Price and } \\
\text { profit relations }\end{array}$} & \multicolumn{3}{|c|}{ Market Size } \\
\hline & & $\alpha_{1}=\alpha_{2}$ & $\alpha_{1}<\alpha_{2}$ & $\alpha_{1}>\alpha_{2}$ \\
\hline \multirow{4}{*}{ Retail price } & $p_{R 1}^{S}>p_{R 1}^{N}$ & $\forall \lambda, \mu \in X$ & $\forall \lambda, \mu \in X$ & $\forall \lambda, \mu \in X$ \\
\hline & $p_{R 2}^{S}<p_{R 2}^{N}$ & Con.3 & Con.6 & Con.13 \\
\hline & $p_{R 1}^{S}>p_{R 2}^{N}$ & $\forall \lambda, \mu \in X$ & Con.7 & $\forall \lambda, \mu \in X$ \\
\hline & $p_{R 2}^{S}<p_{R 1}^{N}$ & Con.3 & Con.8 & $\forall \lambda, \mu \in X$ \\
\hline \multirow{4}{*}{ Distributor price } & $w_{D 1}^{S}<w_{D 1}^{N}$ & Con.4 & Con.9 & Con.14 \\
\hline & $w_{D 2}^{S}<w_{D 2}^{N}$ & $\forall \lambda, \mu \in X$ & $\forall \lambda, \mu \in X$ & $\forall \lambda, \mu \in X$ \\
\hline & $w_{D 1}^{S}<w_{D 2}^{N}$ & Con.4 & $\forall \lambda, \mu \in X$ & Con.15 \\
\hline & $w_{D 2}^{S}<w_{D 1}^{N}$ & $\forall \lambda, \mu \in X$ & Con.10 & $\forall \lambda, \mu \in X$ \\
\hline \multirow{4}{*}{ Manufacturer price } & $w_{M 1}^{S}<w_{M 1}^{N}$ & Con.5 & Con.11 & Con.16 \\
\hline & $w_{M 2}^{S}<w_{M 2}^{N}$ & $\forall \lambda, \mu \in X$ & $\forall \lambda, \mu \in X$ & $\forall \lambda, \mu \in X$ \\
\hline & $w_{M 1}^{S}<w_{M 2}^{N}$ & Con.5 & $\forall \lambda, \mu \in X$ & Con.10 \\
\hline & $w_{M 2}^{S}<w_{M 1}^{N}$ & $\forall \lambda, \mu \in X$ & Con.12 & $\forall \lambda, \mu \in X$ \\
\hline \multirow{4}{*}{$\begin{array}{l}\text { Profit of retailer, } \\
\text { distributor, and } \\
\text { manufacturer }\end{array}$} & $\begin{aligned} \Pi_{R 1}^{S} & <\Pi_{R 1}^{N} \\
\Pi_{D 1}^{S} & <\Pi_{D 1}^{N} \\
\Pi_{M 1}^{S} & <\Pi_{M 1}^{N}\end{aligned}$ & $\forall \lambda, \mu \in X$ & $\forall \lambda, \mu \in X$ & $\forall \lambda, \mu \in X$ \\
\hline & $\begin{aligned} \Pi_{R 1}^{S} & <\Pi_{R 2}^{N} \\
\Pi_{D 1}^{S} & <\Pi_{D 2}^{N} \\
\Pi_{M 1}^{S} & <\Pi_{M 2}^{N}\end{aligned}$ & $\forall \lambda, \mu \in X$ & $\forall \lambda, \mu \in X$ & Con.17 \\
\hline & $\begin{aligned} \Pi_{R 2}^{S} & >\Pi_{R 1}^{N} \\
\Pi_{D 2}^{S} & >\Pi_{D 1}^{N} \\
\Pi_{M 2}^{S} & >\Pi_{M 1}^{N}\end{aligned}$ & $\forall \lambda, \mu \in X$ & $\forall \lambda, \mu \in X$ & Con.18 \\
\hline & $\begin{aligned} \Pi_{R 2}^{S} & >\Pi_{R 2}^{N} \\
\Pi_{D 2}^{S} & >\Pi_{D 2}^{N} \\
\Pi_{M 2}^{S} & >\Pi_{M 2}^{N}\end{aligned}$ & $\forall \lambda, \mu \in X$ & $\forall \lambda, \mu \in X$ & $\forall \lambda, \mu \in X$ \\
\hline \multirow{4}{*}{ Total supply chain profit } & $\Pi_{S C 1}^{S}<\Pi_{S C 1}^{N}$ & $\forall \lambda, \mu \in X$ & $\forall \lambda, \mu \in X$ & $\forall \lambda, \mu \in X$ \\
\hline & $\Pi_{S C 1}^{S}<\Pi_{S C 2}^{N}$ & $\forall \lambda, \mu \in X$ & $\forall \lambda, \mu \in X$ & Con.19 \\
\hline & $\Pi_{S C 2}^{S}>\Pi_{S C 1}^{N}$ & $\forall \lambda, \mu \in X$ & $\forall \lambda, \mu \in X$ & Con.20 \\
\hline & $\Pi_{S C 2}^{S}>\Pi_{S C 2}^{N}$ & $\forall \lambda, \mu \in X$ & $\forall \lambda, \mu \in X$ & $\forall \lambda, \mu \in X$ \\
\hline
\end{tabular}

Table D.1. Conditions (Con.) used in the relations.

\begin{tabular}{|c|c|c|}
\hline Con.1: & & \\
\hline$\lambda=0.1, \mu=0.9(\lambda)$ & $\lambda=0.2,0.3,0.9(\lambda) \leq \mu \leq \lambda-0.01$ & $0.4 \leq \lambda \leq 0.6,0.9(\lambda)-0.01 \leq \mu \leq \lambda-0.01$ \\
\hline $0.7 \leq \lambda \leq 1,0.9(\lambda)-0.02 \leq \mu \leq \lambda-0.01$ & $1.1 \leq \lambda \leq 1.3,0.9(\lambda)-0.03 \leq \mu \leq \lambda-0.01$ & $1.4 \leq \lambda \leq 1.7,0.9(\lambda)-0.04 \leq \mu \leq \lambda-0.01$ \\
\hline \multirow{2}{*}{\multicolumn{3}{|c|}{$\begin{array}{l}1.8 \leq \lambda \leq 2,0.9(\lambda)-0.05 \leq \mu \leq \lambda-0.01 \\
\text { Con.2: }\end{array}$}} \\
\hline & & \\
\hline $0.3 \leq \lambda \leq 0.5, \mu=\lambda-0.01$ & $0.6 \leq \lambda \leq 0.8, \lambda-0.02 \leq \mu \leq \lambda-0.01$ & $0.9 \leq \lambda \leq 1.1, \lambda-0.03 \leq \mu \leq \lambda-0.01$ \\
\hline$\lambda=1.2,1.3, \lambda-0.04 \leq \mu \leq \lambda-0.01$ & $1.4 \leq \lambda \leq 1.6, \lambda-0.05 \leq \mu \leq \lambda-0.01$ & $1.7 \leq \lambda \leq 1.9, \lambda-0.06 \leq \mu \leq \lambda-0.01$ \\
\hline \multicolumn{3}{|l|}{$\lambda=2, \lambda-0.07 \leq \mu \leq \lambda-0.01$} \\
\hline \multicolumn{3}{|l|}{ Con.3: } \\
\hline $0.1 \leq \lambda \leq 0.5,0.01 \leq \mu \leq 0.05(10 \lambda)$ & $0.6 \leq \lambda \leq 1,0.01 \leq \mu \leq 0.05(10 \lambda)+0.01$ & $1.1 \leq \lambda \leq 1.6 ; 0.01 \leq \mu \leq 0.05(10 \lambda)+0.02$ \\
\hline \multicolumn{3}{|l|}{$1.7 \leq \lambda \leq 2,0.01 \leq \mu \leq 0.05(10 \lambda)+0.03$} \\
\hline \multicolumn{3}{|l|}{ Con.4: } \\
\hline$\lambda=0.3,0.4, \mu=\lambda-0.01$ & $\lambda=0.5,0.6, \lambda-0.02 \leq \mu \leq \lambda-0.01$ & $\lambda=0.7,0.8, \lambda-0.03 \leq \mu \leq \lambda-0.01$ \\
\hline$\lambda=0.9,1, \lambda-0.04 \leq \mu \leq \lambda-0.01$ & $\lambda=1.1,1.2, \lambda-0.05 \leq \mu \leq \lambda-0.01$ & $\lambda=1.3,1.4, \lambda-0.06 \leq \mu \leq \lambda-0.01$ \\
\hline$\lambda=1.5,1.6, \lambda-0.07 \leq \mu \leq \lambda-0.01$ & $1.7 \leq \lambda \leq 1.9, \lambda-0.08 \leq \mu \leq \lambda-0.01$ & $\lambda=2, \lambda-0.09 \leq \mu \leq \lambda-0.01$ \\
\hline
\end{tabular}


Table D.1. Conditions (Con.) used in the relations (continued).

\begin{tabular}{|c|c|c|}
\hline Con.5: & & \\
\hline$\lambda=0.1,0.20 .01 \leq \mu \leq 0.5(\lambda)$ & $\lambda=0.3,0.4,0.01 \leq \mu \leq 0.5(\lambda)+0.01$ & $\lambda=0.5,0.6,0.01 \leq \mu \leq 0.5(\lambda)+0.02$ \\
\hline$\lambda=0.7,0.8,0.01 \leq \mu \leq 0.5(\lambda)+0.03$ & $\lambda=0.9,1,0.01 \leq \mu \leq 0.5(\lambda)+0.04$ & $\lambda=1.1,1.2,0.01 \leq \mu \leq 0.5(\lambda)+0.05$ \\
\hline$\lambda=1.3,1.4,0.01 \leq \mu \leq 0.5(\lambda)+0.06$ & $\lambda=1.5,1.6,0.01 \leq \mu \leq 0.5(\lambda)+0.07$ & $\lambda=1.7,1.8,0.01 \leq \mu \leq 0.5(\lambda)+0.08$ \\
\hline \multicolumn{3}{|l|}{$\lambda=1.9,2,0.01 \leq \mu \leq 0.5(\lambda)+0.09$} \\
\hline \multicolumn{3}{|l|}{ Con.6: } \\
\hline $0.1 \leq \lambda \leq 1.2,0.01 \leq \mu<0.07(10 \lambda)$ & & $1.3 \leq \lambda \leq 2,0.01 \leq \mu<0.07(10 \lambda)-1$ \\
\hline \multicolumn{3}{|l|}{ Con.7: } \\
\hline$\lambda=0.2, \mu=\lambda-0.01$ & $0.3 \leq \lambda \leq 0.5 ; 0.9(\lambda)+0.01 \leq \mu \leq \lambda-0.01$ & $0.6 \leq \lambda \leq 1 ; 0.9(\lambda)+0.02 \leq \mu \leq \lambda-0.01$ \\
\hline $1.1 \leq \lambda \leq 1.5 ; 0.9(\lambda)+0.03 \leq \mu \leq \lambda-0.01$ & $1.6 \leq \lambda \leq 2 ; 0.9(\lambda)+0.04 \leq \mu \leq \lambda-0.01$ & \\
\hline \multicolumn{3}{|l|}{ Con.8: } \\
\hline $0.7 \leq \lambda \leq 1.3, \mu=\lambda-0.01$ & & $1.4 \leq \lambda \leq 2, \lambda-0.02 \leq \mu \leq \lambda-0.01$ \\
\hline \multicolumn{3}{|l|}{ Con.9: } \\
\hline$\lambda=0.2,0.3, \mu=\lambda-0.01$ & $\lambda=0.4, \lambda-0.02 \leq \mu \leq \lambda-0.01$ & $\lambda=0.5,0.6, \lambda-0.03 \leq \mu \leq \lambda-0.01$ \\
\hline$\lambda=0.7, \lambda-0.04 \leq \mu \leq \lambda-0.01$ & $\lambda=0.8,0.9, \lambda-0.05 \leq \mu \leq \lambda-0.01$ & $\lambda=1, \lambda-0.06 \leq \mu \leq \lambda-0.01$ \\
\hline$\lambda=1.1,1.2, \lambda-0.07 \leq \mu \leq \lambda-0.01$ & $\lambda=1.3,1.4, \lambda-0.08 \leq \mu \leq \lambda-0.01$ & $\lambda=1.5, \lambda-0.09 \leq \mu \leq \lambda-0.01$ \\
\hline$\lambda=1.6,1.7, \lambda-0.1 \leq \mu \leq \lambda-0.01$ & $\lambda=1.8, \lambda-0.11 \leq \mu \leq \lambda-0.01$ & $\lambda=1.9,2, \lambda-0.12 \leq \mu \leq \lambda-0.01$ \\
\hline \multicolumn{3}{|l|}{ Cone.10: } \\
\hline$\lambda=0.2, \mu=0.9(\lambda)+0.01$ & $\lambda=0.3,0.9(\lambda)+0.01 \leq \mu \leq \lambda-0.01$ & $0.4 \leq \lambda \leq 0.6,0.9(\lambda)+0.02 \leq \mu \leq \lambda-0.01$ \\
\hline $0.7 \leq \lambda \leq 0.9,0.9(\lambda)+0.03 \leq \mu \leq \lambda-0.01$ & $1 \leq \lambda \leq 1.2,0.9(\lambda)+0.04 \leq \mu \leq \lambda-0.01$ & $1.3 \leq \lambda \leq 1.5,0.9(\lambda)+0.05 \leq \mu \leq \lambda-0.01$ \\
\hline $1.6 \leq \lambda \leq 1.8,0.9(\lambda)+0.06 \leq \mu \leq \lambda-0.01$ & $\lambda=1.9,2,0.9(\lambda)+0.07 \leq \mu \leq \lambda-0.01$ & \\
\hline \multicolumn{3}{|l|}{ Con.11: } \\
\hline $0.1 \leq \lambda \leq 1.2,0.01 \leq \mu \leq 0.04(10 \lambda)$ & & $1.3 \leq \lambda \leq 2,0.01 \leq \mu \leq 0.04(10 \lambda)-1$ \\
\hline \multicolumn{3}{|l|}{ Con.12: } \\
\hline$\lambda=0.1, \mu=0.9(\lambda)$ & $\lambda=0.2,0.9(\lambda) \leq \mu \leq \lambda-0.01$ & $0.3 \leq \lambda \leq 0.5,0.9(\lambda)-0.01 \leq \mu \leq \lambda-0.01$ \\
\hline$\lambda=0.6 .0 .7,0.9(\lambda)-0.02 \leq \mu \leq \lambda-0.01$ & $0.8 \leq \lambda \leq 1,0.9(\lambda)-0.03 \leq \mu \leq \lambda-0.01$ & $1.1 \leq \lambda \leq 1.3,0.9(\lambda)-0.04 \leq \mu \leq \lambda-0.01$ \\
\hline $1.4 \leq \lambda \leq 1.6,0.9(\lambda)-0.05 \leq \mu \leq \lambda-0.01$ & $\lambda=1.7,1.8,0.9(\lambda)-0.06 \leq \mu \leq \lambda-0.01$ & $\lambda=1.9,2,0.9(\lambda)-0.07 \leq \mu \leq \lambda-0.01$ \\
\hline \multicolumn{3}{|l|}{ Con.13: } \\
\hline$\lambda=0.1,0.2,0.01 \leq \mu \leq 0.05(10 \lambda)$ & $\lambda=0.3,0.4,0.01 \leq \mu \leq 0.05(10 \lambda)+0.01$ & $\lambda=0.5,0.6,0.01 \leq \mu \leq 0.05(10 \lambda)+0.02$ \\
\hline$\lambda=0.7,0.8,0.01 \leq \mu \leq 0.05(10 \lambda)+0.03$ & $\lambda=0.9,1,0.01 \leq \mu \leq 0.05(10 \lambda)+0.04$ & $\lambda=1.1,1.2,0.01 \leq \mu \leq 0.05(10 \lambda)+0.05$ \\
\hline$\lambda=1.3,1.4,0.01 \leq \mu \leq 0.05(10 \lambda)+0.06$ & $\lambda=1.5,1.6,0.01 \leq \mu \leq 0.05(10 \lambda)+0.07$ & $\lambda=1.7,1.8,0.01 \leq \mu \leq 0.05(10 \lambda)+0.08$ \\
\hline \multicolumn{3}{|l|}{$\lambda=1.9,2,0.01 \leq \mu \leq 0.05(10 \lambda)+0.09$} \\
\hline \multicolumn{3}{|l|}{ Con.14: } \\
\hline $0.1 \leq \lambda \leq 1.2,0.4(\lambda)+0.01 \leq \mu \leq \lambda-0.01$ & & $1.3 \leq \lambda \leq 2,0.4(\lambda) \leq \mu \leq \lambda-0.01$ \\
\hline \multicolumn{3}{|l|}{ Con.15: } \\
\hline $09 \leq \lambda \leq 1.7, \mu=\lambda-0.01$ & & $1.8 \leq \lambda \leq 2, \lambda-0.02 \leq \mu \leq \lambda-0.01$ \\
\hline \multicolumn{3}{|l|}{ Con.16: } \\
\hline$\lambda=0.1,, 0.7(\lambda) \leq \mu \leq \lambda-0.01$ & $\lambda=0.2,0.3,0.7(\lambda)-0.01 \leq \mu \leq \lambda-0.01$ & $\lambda=0.4,0.5,0.7(\lambda)-0.02 \leq \mu \leq \lambda-0.01$ \\
\hline$\lambda=0.6 .0 .7,0.7(\lambda)-0.03 \leq \mu \leq \lambda-0.01$ & $\lambda=0.8 .0 .9,0.7(\lambda)-0.04 \leq \mu \leq \lambda-0.01$ & $\lambda=1,1.1,0.7(\lambda)-0.05 \leq \mu \leq \lambda-0.01$ \\
\hline$\lambda=1.2,1.3,0.7(\lambda)-0.06 \leq \mu \leq \lambda-0.01$ & $\lambda=1.4,1.5,0.7(\lambda)-0.07 \leq \mu \leq \lambda-0.01$ & $\lambda=1.6,1.7,, 0.7(\lambda)-0.08 \leq \mu \leq \lambda-0.01$ \\
\hline$\lambda=1.8,1.9,0.7(\lambda)-0.09 \leq \mu \leq \lambda-0.01$ & $\lambda=2,0.7(\lambda)-0.1 \leq \mu \leq \lambda-0.01$ & \\
\hline \multicolumn{3}{|l|}{ Con.17: } \\
\hline $0.1 \leq \lambda \leq 0.5,0.8(\lambda) \leq \mu \leq \lambda-0.01$ & & $0.6 \leq \lambda \leq 2,0.8(\lambda)+0.01 \leq \mu \leq \lambda-0.01$ \\
\hline \multicolumn{3}{|l|}{ Con.18: } \\
\hline $0.1 \leq \lambda \leq 0.5,0.7(\lambda) \leq \mu \leq \lambda-0.01$ & $0.6 \leq \lambda \leq 1.2,0.7(\lambda)-0.01 \leq \mu \leq \lambda-0.01$ & $1.3 \leq \lambda \leq 2,0.7(\lambda)-0.02 \leq \mu \leq \lambda-0.01$ \\
\hline \multicolumn{3}{|l|}{ Con.19: } \\
\hline $0.1 \leq \lambda \leq 0.3,0.7(\lambda) \leq \mu \leq \lambda-0.01$ & & $0.4 \leq \lambda \leq 2,0.7(\lambda)+0.01 \leq \mu \leq \lambda-0.01$ \\
\hline \multicolumn{3}{|l|}{ Con.20: } \\
\hline $0.1 \leq \lambda \leq 0.3,0.8(\lambda) \leq \mu \leq \lambda-0.01$ & $0.4 \leq \lambda \leq 0.6,0.8(\lambda)-0.01 \leq \mu \leq \lambda-0.01$ & $0.7 \leq \lambda \leq 0.9,0.8(\lambda)-0.02 \leq \mu \leq \lambda-0.01$ \\
\hline $1 \leq \lambda \leq 1.2,0.8(\lambda)-0.03 \leq \mu \leq \lambda-0.01$ & $1.3 \leq \lambda \leq 1.6,0.8(\lambda)-0.04 \leq \mu \leq \lambda-0.01$ & $1.7 \leq \lambda \leq 2,0.8(\lambda)-0.05 \leq \mu \leq \lambda-0.01$ \\
\hline \multicolumn{3}{|l|}{ Con.21: } \\
\hline$\lambda=0.2,0.3,0.9(\lambda)+0.01 \leq \mu \leq \lambda-0.01$ & $0.4 \leq \lambda \leq 0.7,0.9(\lambda)+0.02 \leq \mu \leq \lambda-0.01$ & $0.8 \leq \lambda \leq 1,0.9(\lambda)+0.03 \leq \mu \leq \lambda-0.01$ \\
\hline $1.1 \leq \lambda \leq 1.4,0.9(\lambda)+0.04 \leq \mu \leq \lambda-0.01$ & $1.5 \leq \lambda \leq 1.7,0.9(\lambda)+0.05 \leq \mu \leq \lambda-0.01$ & $1.8 \leq \lambda \leq 2,0.9(\lambda)+0.06 \leq \mu \leq \lambda-0.01$ \\
\hline \multicolumn{3}{|l|}{ Con.22: } \\
\hline $0.1 \leq \lambda \leq 0.3,0.01 \leq \mu \leq 0.6(\lambda)$ & $0.4 \leq \lambda \leq 0.6,0.01 \leq \mu \leq 0.6(\lambda)+0.01$ & $\lambda=0.7,0.8,0.01 \leq \mu \leq 0.6(\lambda)+0.02$ \\
\hline $0.9 \leq \lambda \leq 1.1,0.01 \leq \mu \leq 0.6(\lambda)+0.03$ & $1.2 \leq \lambda \leq 1.4,0.01 \leq \mu \leq 0.6(\lambda)+0.04$ & $\lambda=1.5,1.6,0.01 \leq \mu \leq 0.6(\lambda)+0.05$ \\
\hline $1.7 \leq \lambda \leq 1.9,0.01 \leq \mu \leq 0.6(\lambda)+0.06$ & $\lambda=2,0.01 \leq \mu \leq 0.6(\lambda)+0.07$ & \\
\hline
\end{tabular}




\section{Biographies}

Narges Khanlarzade received her MSc in Faculty of Industrial \& Systems Engineering at Tarbiat Modares University in 2011 and currently is a PhD candidate of Industrial Engineering in Faculty of Industrial \& Systems Engineering at Tarbiat Modares University. Her research interests include supply chain management, inventory control, and game theory.

Seyed Hesameddin Zegordi is a Professor of Industrial Engineering in the Faculty of Industrial \& Systems Engineering at Tarbiat Modares University, Iran. He received his $\mathrm{PhD}$ degree from the Department of Industrial Engineering and Management at Tokyo Institute of Technology, Japan in 1994. He holds an MSc degree in Industrial Engineering and Systems from Sharif University of Technology, Iran and a BSc degree in Industrial Engineering from Isfahan University of Technology, Iran. His main areas of teaching and research interests include production planning and scheduling, multi-objective optimization problems, meta-heuristics, quality management, and productivity. He has published several articles in international conferences and academic journals including European Journal of Operational Research, International Journal of Production Research, Journal of Operational Research Society of Japan, Computers \& Industrial Engineering, Amirkabir Journal of Science and Engineering, and Scientia Iranica: International Journal of Science and Technology.

Isa Nakhai Kamalabadi is a Professor of Industrial Engineering at University of Kurdistan. He received his BSc degree in Computer Science and its applications from Shahid Beheshti University, Iran in 1979, his MSc degree in Industrial Engineering from Tarbiat Modares University, Iran, in 1988, and his PhD degree in Industrial Engineering from University of Toronto in 1995. He is currently working as a Professor at University of Kurdistan and as a Joint Professor at Tarbiat Modares University, Iran. His research interests include optimization, supply chain management, scheduling, and information technology. 